Published in final edited form as:

J Am Chem Soc. 2016 May 11; 138(18): 6010-6019. doi:10.1021/jacs.6b02486.

\title{
Nanoscale Coordination Polymers Codeliver Chemotherapeutics and siRNAs to Eradicate Tumors of Cisplatin-Resistant Ovarian Cancer
}

\author{
Chunbai He $^{\dagger}$, Christopher Poon ${ }^{\dagger}$, Christina Chan ${ }^{\dagger}$, S. Diane Yamada ${ }^{\ddagger}$, and Wenbin Lin ${ }^{*}, \dagger$ \\ tDepartment of Chemistry, The University of Chicago, Chicago, Illinois 60637, United States \\ ¥Department of Obstetrics and Gynecology, Section of Gynecologic Oncology, The University of \\ Chicago, Chicago, Illinois 60637, United States
}

\begin{abstract}
Drug resistance impedes the successful treatment of many types of cancers, especially ovarian cancer (OCa). To counter this problem, we developed novel long-circulating, self-assembled coreshell nanoscale coordination polymer (NCP) nanoparticles that efficiently deliver multiple therapeutics with different mechanisms of action to enhance synergistic therapeutic effects. These NCP particles contain high payloads of chemotherapeutics cisplatin or cisplatin plus gemcitabine in the core and pooled siRNAs that target multidrug resistant (MDR) genes in the shell. The NCP particles possess efficient endosomal escape via a novel carbon dioxide release mechanism without compromising the neutral surface charge required for long blood circulation and effectively downregulate MDR gene expression in vivo to enhance chemotherapeutic efficacy by several orders of magnitude. Even at low doses, intraperitoneal injections of nanoparticles led to effective and long-lasting tumor regression/eradication in subcutaneous and intraperitoneal xenograft mouse models of cisplatin-resistant OCa. By silencing MDR genes in tumors, selfassembled core-shell nanoparticles promise a more effective chemotherapeutic treatment for many challenging cancers.
\end{abstract}

\section{Graphical Abstract}

\footnotetext{
*Corresponding Author: wenbinlin@uchicago.edu.

Supporting Information

The Supporting Information is available free of charge on the ACS Publications website at DOI: 10.1021/jacs.6b02486.

Procedures and supporting results for flow cytometry, synthesis, characterization, and in vitro/vivo evaluations of NCP-2/siRNAs. (PDF)

Notes

The authors declare no competing financial interest.
} 


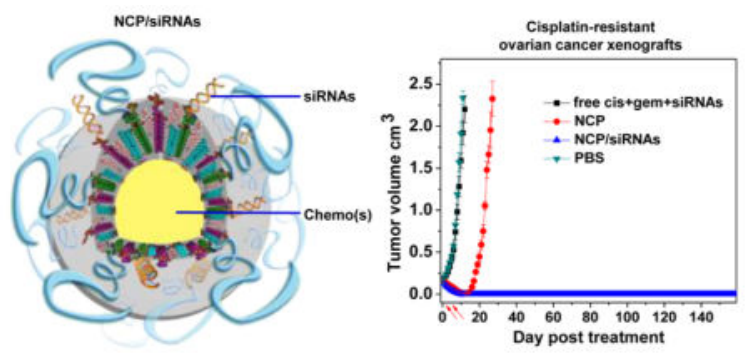

\section{INTRODUCTION}

Ovarian cancer ( $\mathrm{OCa}$ ) is the fifth leading cause of death by cancer for women in the United States, accounting for $5 \%$ of cancer mortalities in this population. ${ }^{1}$ Most patients present with advanced disease and are treated with upfront surgery followed by platinum/taxanebased chemotherapy, but the majority have tumors that either do not respond to chemotherapy or will eventually recur with multidrug resistant (MDR) OCa. ${ }^{2-10}$ Intrinsically resistant and recurring ovarian cancers are terminal diseases that cannot be cured with existing therapeutics. ${ }^{3,6}$ Thus, there is clearly an urgent need to develop novel therapeutic strategies to overcome drug resistance in OCa.

Tumors may possess intrinsic or acquired drug resistance mechanisms that differ from patient to patient. ${ }^{2-5,11-13}$ Moreover, cancer cells within one tumor can exhibit significant genetic heterogeneity with respect to the signaling pathways that promote drug resistance. ${ }^{14,15}$ Small interfering RNA (siRNA) has the ability to disrupt cellular MDR pathways by silencing the expression of relevant genes. ${ }^{16-25}$ Simultaneously delivering pooled siRNAs targeting multiple distinct molecular signaling pathways would provide an effective approach to overcoming drug resistance in OCa. ${ }^{22,23,26}$ We hypothesized that coadministration of chemotherapeutics and siRNAs targeting MDR genes can increase the efficacy of existing OCa treatments.

Because of the instability of siRNAs in systemic circulation and their inability to cross cell membranes, siRNAs must be either synthetically modified or delivered by effective vehicles to elicit gene silencing in vivo. Although nanoparticulate delivery systems have been shown to improve anticancer efficacy of chemotherapeutics, ${ }^{27-37}$ efficient delivery of siRNAs to cancer cells in vivo has remained an unsolved problem due to the contradictory surface charge requirements for efficient endosomal escape (cationic) and long blood circulation (neutral). Although cationic lipids have been combined with nanoscale coordination polymers for the codelivery of cisplatin and pooled siRNAs to regress tumor growth in a cisplatin-resistant OCa mouse model via intratumoral injection, ${ }^{38}$ such delivery systems exhibited poor pharmacokinetics and biodistribution upon systemic administration and are unsuitable for clinical translation.

We herein report a robust self-assembled, core-shell nanoscale coordination polymer (NCP)based nanomedicine platform for the codelivery of chemotherapeutic agent(s) and siRNAs targeting MDR genes for the effective treatment of resistant OCa. The novel nanomedicine, NCP-1/siRNAs, carries cisplatin in the core and siRNAs in the lipid layer with built-in 
mechanisms for triggered release and endosomal escape and shows prolonged blood circulation, improved tumor uptake, and enhanced anticancer efficacy in subcutaneous and intraperitoneal xenograft mouse models of resistant OCa. By modifying the nanoparticle core to include gemcitabine, the resulting NCP-2/siRNAs particles retained all of the above merits while simultaneously potentiating anticancer efficacy. Given the dramatically improved therapeutic windows of NCP-1/siRNAs and NCP-2/siRNAs, we believe that these particles hold great promise for clinical translation for the treatment of resistant OCa.

\section{RESULTS}

\section{Synthesis and Characterization of NCP-1/siRNAs}

1,2-Dioleoyl-sn-glycero-3-phosphate (DOPA)-capped NCP-1 particles containing a cisplatin prodrug, cis,cis,trans-[Pt- $\left.\left(\mathrm{NH}_{3}\right)_{2} \mathrm{Cl}_{2}\left(\mathrm{OCONHP}(\mathrm{O})(\mathrm{OH})_{2}\right)_{2}\right](\mathrm{PtBp})$, were synthesized according to our previous report. ${ }^{39}$ We developed a strategy to incorporate siRNA in the shell while being shielded by the PEG layer to prevent nuclease degradation in physiological environments. N-succinimidyl-3-(2-pyridyldithio)propionyl-1,2-distearoyl-sn-glycero-3phosphoethanolamine (DSPE-SPDP) was synthesized from succinimidyl 3-(2pyridyldithio)propionate and 1,2-distearoyl-sn-glycero-3-phosphoethanolamine, and further conjugated with thiol siRNA (IDT, USA) to afford the DSPE-siRNA conjugate. The disulfide linkage is placed on the $5^{\prime}$ end of sense strand of siRNA duplexes in order to avoid potential inhibition on the antisense strand. DOPA-NCP-1 particles were then coated with cholesterol, DOPC, DSPE-siRNA conjugates, and 20 mol \% DSPE-PEG2k to afford a coreshell nanostructure with a solid core carrying chemotherapeutics and a lipid layer containing siRNAs (Figure 1A). Transmission electron microscopy (TEM) images indicated that NCP-1/siRNAs form spherical particles (Figure 1B). The Z-average size, PDI, and zeta potential of NCP-1/siRNAs were $105.3 \pm 6.2 \mathrm{~nm}, 0.112 \pm 0.004$, and $-4.8 \pm 1.3 \mathrm{mV}$, respectively, by DLS measurement. The cisplatin loading was determined to be $25 \mathrm{wt} \%$ by inductively coupled plasma-mass spectrometry (ICP-MS) and the siRNA loading was $6 \mathrm{wt}$ $\%$ by Quant-iT RiboGreen RNA kit. The siRNA release of NCP-1/siRNAs was evaluated in PBS supplemented with $4.5 \mu \mathrm{M}$ glutathione (GSH, extracellular environment) or $10 \mathrm{mM}$ GSH (intracellular environment). siRNA release was slow in PBS without GSH, but significantly enhanced in PBS containing $10 \mathrm{mM}$ GSH (Figure 1C). Inside cells, the disulfide bond of DSPE-siRNA was rapidly cleaved by a reducing agent, which led to enhanced siRNA release. We evaluated the capability of NCP-1/siRNAs to protect siRNAs from nuclease degradation by incubating NCP-1/siRNAs with serum and observing siRNA integrity by gel electrophoresis analysis over time. As depicted in Figure 1D, the intensity of free siRNA bands decreased rapidly with time; $~ 46 \%$ of the siRNA maintained its integrity in the DSPE-siRNA conjugate after $24 \mathrm{~h}$, only one-half of the $~ 91.9 \%$ of siRNA intact after loading onto NCP-1/siRNAs (Figure S2), suggesting that NCP-1/siRNAs effectively protected siRNA from degradation by nucleases in the serum.

\section{Efficient Endosomal Escape}

NCP-1/siRNAs have a novel built-in endosomal escape mechanism that is not reliant on cationic excipients. Two carbon dioxide molecules are generated as byproducts of the intracellular release of cisplatin (Figure 2A), which we hypothesize can change the osmotic 
pressure to disrupt the endosomal membrane, facilitating the escape of siRNAs from endosomal entrapment and triggering the formation of RNA-induced silencing complexes (RISCs) in the cytoplasm to mediate gene silencing (Figure 2B).

The efficient generation of $\mathrm{CO}_{2}$ was first confirmed in a solution, where we observed efficient $\mathrm{CO}_{2}$ generation from PtBp in reducing environments. Vigorous gas bubbling was observed when $5 \mathrm{mM}$ cysteine (Cys) was added to a solution of PtBp in PBS, but no gas generation was noted before the addition of Cys. The identity of the gas was confirmed to be $\mathrm{CO}_{2}$ by gas chromatography, which displayed a peak with a retention time identical to that of authentic $\mathrm{CO}_{2}$ (Figure S3).

We used confocal laser scanning microscopy (CLSM) to evaluate endosomal escape efficiency of Alexa Fluor 647 labeled NCP-1/siRNAs (NCP-1/Alexa-siRNAs) in A2780/ CDDP cells. Human OCa cells A2780/CDDP were incubated with NCP-1/Alexa-siRNAs for different time periods, fixed, stained with Lysotracker Green and DAPI, and observed by CLSM. The colocalization of green fluorescence (Lysotracker Green-stained endosome) and red fluorescence (Alexa Fluor 647-labeled siRNA) was calculated by ImageJ. NCP-1/AlexasiRNAs was rapidly internalized by cells, evidenced by the colocalization of siRNA and endosome/lysosome. A linear decrease in colocalization occurred over 30 min, indicating that siRNAs can successfully escape endosomal entrapment and form RISCs in the cytoplasm (Figure 2C, D).

\section{In Vitro Transfection Efficiency and Cytotoxicity}

NCP-1/siRNAs successfully overcame several key barriers to gene transfection, including siRNA encapsulation, protection, release, and endosomal escape. As a result, NCP-1/ siRNAs evoked potent gene silencing, significantly reducing mRNA expression (Figure 3A, C) and protein production (Figure 3B, D) in two cisplatin-resistant ovarian cancer cell lines: SKOV-3 and A2780/CDDP. We compared the gene silencing efficiency of NCP-1/siRNAs containing two siRNAs to those containing only an individual siRNA to determine if there was synergy in the siRNA downregulation of relevant proteins responsible for drug resistance. Pooled siRNAs in NCP-1/siRNAs contain the same total siRNA dose as that of NCP-1/individual siRNA, with each individual siRNA contributing equally. Unappreciable differences were noticed for the specific gene silencing efficiency between treatment groups, suggesting that pooled siRNAs may work synergistically to silence multiple drug-resistant genes. At a total siRNA dose of $6 \mathrm{nM}, \mathrm{NCP}-1 / \mathrm{siRNAs}$ efficiently downregulated both survivin and Bcl-2 gene expression in SKOV-3 and A2780/CDDP cells by $>70 \%$, as determined by Realtime-PCR and enzyme-linked immunosorbent assays (ELISA). For SKOV-3 cells, NCP-1/siRNAs outperformed the industry standard Lipofectamine RNAiMAX at $3 \mathrm{nM}$ in gene silencing $(33.9 \pm 2.88 \%$ vs $52.8 \pm 3.6 \%)$. ELISA quantification indicated that NCP-1/sisurvivin reduced protein expression ( $75 \%$ downregulation) in SKOV-3 cells for up to 4 days (Figure S4).

Efficient gene silencing dramatically enhanced the efficacy of NCP-1/siRNAs compared to free cisplatin with free siRNAs, NCP-1, and Zn Control/siRNAs in the two cisplatinresistant ovarian cancer cell lines SKOV-3 and A2780/CDDP. By codelivering cisplatin and two siRNAs, NCP-1/siRNAs resensitized the cells to platinum drug treatment, drastically 
decreasing the dose of a drug required for $50 \%$ inhibition $\left(\mathrm{IC}_{50}\right)$ of cisplatin relative to that of free cisplatin with free siRNAs or NCP-1. As shown in Table 1 and Figure S5-S7, the cisplatin $\mathrm{IC}_{50}$ of NCP-1/siRNAs decreased by 2 orders of magnitude, specifically a 368- and 113-fold decrease compared to free cisplatin with siRNAs in SKOV-3 and A2780/CDDP cells, respectively. In comparison, NCP-1/individual siRNA was still more potent than NCP-1 but less powerful than NCP-1/pooled siRNAs, indicating that simultaneously silencing two MDR genes was more effective than targeting a single gene in overcoming drug resistance. NCP-1 alone did not significantly differ from free cisplatin with siRNAs in cytotoxicity. In contrast, in the cisplatin-sensitive ovarian cancer cell line A2780, we observed similar cytotoxicity in all five treatment groups. This result further confirmed our hypothesis: the efficient knockdown of MDR genes by NCP-1/siRNAs is vital to enhancing chemotherapeutic cytotoxicity in drug-resistant cells.

The ability of NCP-1/siRNAs to induce apoptosis in the cisplatin-resistant cell lines A2780/ CDDP and SKOV-3 and the cisplatin-sensitive cell line A2780 was examined by Annexin V/PI staining followed by flow cytometry. After $24 \mathrm{~h}$ incubation with $\mathrm{Zn}$ control/siRNAs, cells remained healthy with no observed apoptosis. NCP-1/siRNAs treatment yielded $>90 \%$ apoptosis in all 3 cell lines, similar to NCP-1 and free cisplatin with siRNAs in A2780, but $\sim 3 \times$ that of the other treatments in A2780/CDDP or SKOV-3 (Figure S8-S10 and Table S1). This further substantiates our hypothesis that the efficient gene silencing mediated by NCP-1/siRNAs resensitized the resistant cells to cisplatin treatment.

\section{In Vivo Pharmacokinetic and Biodistribution}

The pharmacokinetics and biodistribution of NCP-1/siRNAs was carried out on CT26 tumor-bearing Balb/c mice by intravenous or intraperitoneal injection (Figure 4). The platinum distribution was quantified by ICP-MS and the serum siRNA amount was quantified by fluorimetry (excitation: $650 \mathrm{~nm}$; emission: $670 \mathrm{~nm}$ ). By i.v. injection, both the cisplatin and siRNA concentrations in blood were best fit by a one-compartment model with nonlinear elimination, with blood circulation half-lives of $10.2 \pm 0.6$ and $10.7 \pm 1.2 \mathrm{~h}$, respectively. The ratio of cisplatin to siRNA remained consistent in the blood for up to $48 \mathrm{~h}$ post injection, suggesting that NCP-1/siRNAs remained structurally intact during both abdominal absorption and systemic circulation. In addition to the prolonged blood circulation time, tissue distribution profiles of NCP-1/siRNAs showed a resistance to uptake by the mononuclear phagocyte system (MPS), as evidenced by the low $\% \mathrm{ID} / \mathrm{g}$ (percent injected dose/gram tissue) in the liver ( $<5.5 \pm 1.6 \% \mathrm{ID} / \mathrm{g}$ for i.v. and $<9.7 \pm 5.6 \% \mathrm{ID} / \mathrm{g}$ for i.p.), lung ( $<2.2 \pm 0.1 \% \mathrm{ID} / \mathrm{g}$ for i.v. and $<8.2 \pm 2.2 \% \mathrm{ID} / \mathrm{g}$ for i.p.), and kidney ( $<6.6$ $\pm 0.7 \% \mathrm{ID} / \mathrm{g}$ for i.v. and $<4.1 \pm 0.6 \% \mathrm{ID} / \mathrm{g}$ for i.p.). More importantly, NCP-1/siRNAs achieved a peak tumor uptake of $14.6 \pm 6.8 \% \mathrm{ID} / \mathrm{g}$ by i.p. injection compared to $6.1 \pm 1.1 \%$ ID/g by i.v. injection at $24 \mathrm{~h}$ post injection. We hypothesized that the low nonspecific uptake by normal tissue combined with high tumor accumulation of NCP-1/siRNAs could dramatically improve the therapeutic window.

\section{Anticancer Efficacy in a Subcutaneous Xenograft OCa Mouse Model}

We evaluated the in vivo antitumor effect of NCP-1/siRNAs in cisplatin-resistant SKOV-3 subcutaneous xenografts by two different methods of systemic injection with equivalent 
cisplatin $(0.75 \mathrm{mg} / \mathrm{kg})$ and siRNA doses $(0.18 \mathrm{mg} / \mathrm{kg})$, where applicable. The treatment started when the tumors reached $\sim 120 \mathrm{~mm}^{3}$. As depicted in Figure 5A, no antitumor efficacy was observed for free cisplatin with free siRNAs, NCP-1, Zn Control/siRNAs, or NCP-1/ctrl siRNA (NCP-1 loaded with universal control siRNA). In contrast, NCP-1/siRNAs controlled tumor growth or caused remarkable tumor regression.

Compared to control groups, NCP-1/siRNAs injected intravenously every 3 days for a total of three injections significantly reduced the mRNA expression levels of the targeted genes by $63.4 \%$ and $68.6 \%$ for Bcl-2 and survivin, respectively (Figure 5B). The significant knockdown of the targeted genes in the tumor site presumably sensitized the tumor cells to cisplatin treatment, successfully repressing tumor growth. Notably, NCP-1/siRNAs injected intraperitoneally every 3 days for a total of two injections led to complete tumor eradication in 5 out of 6 mice. Because only one tumor remained after treatment with NCP-1/siRNAs by i.p. injection, we were unable to further analyze the gene expression and apoptosis of the tumors in this group. These results strongly support our hypothesis that codelivering cisplatin and siRNAs by NCP-1/siRNAs resensitized resistant OCa to cisplatin treatment, achieving superior anticancer efficacy compared to monotherapies.

Moreover, no significant loss of body weight or immunogenic response was observed, suggesting treatments were well tolerated (Figure 5D and Figure S14). TUNEL assay of tumors showed DNA fragmentation (Figure 5C), indicating the relative percentage of apoptotic cells (Figure S15) was significantly greater in the NCP-1/siRNAs group than those in the other groups.

We also performed histopathological analysis of the kidneys, livers, spleens, and lungs of the mice treated with NCP-1/siRNAs to evaluate toxicity (Figure S16). NCP-1/siRNAs treatment did not lead to cast formation, swelling, desquamation, tubular damage, or microvillus disappearance in the kidneys, suggesting there was negligible nephrotoxicity. No hemorrhages or dystrophy of hepatocytes was observed in the livers. NCP-1/siRNAs did not increase the number of lymphoid follicles in the spleens or cause inflammatory cell infiltration in the lungs.

The maximum tolerated dose (MTD) of NCP-1/siRNAs, that is, the highest dose tolerated by $100 \%$ of mice after a single i.p. injection to female BALB/c mice, was determined to be $\geq 4 \mathrm{mg}$ cisplatin/ $\mathrm{kg}$. At a total cisplatin dose of only $1.5 \mathrm{mg} / \mathrm{kg}$ by i.p. injection, NCP-1/ siRNAs achieved tumor eradication in 5 out of 6 mice. Therefore, the therapeutic window of NCP-1/siRNAs by i.p. injection is greater than 2.67, a great improvement over the existing cisplatin regimen.

\section{Anticancer Efficacy of NCP-1/siRNAs in an Intra-peritoneal Xenograft OCa Mouse Model}

The anticancer efficacy of NCP-1/siRNAs was examined in a cisplatin-resistant A2780/ CDDP intraperitoneal xenograft mouse model. The survival benefit and tumor inhibition results were obtained in two separate studies. To study survival, $10^{5}$ A2780/CDDP cells were i.p. injected into female athymic nude mice to establish the intraperitoneal xenograft model. Beginning 6 days after tumor inoculation, mice were treated once every 3 days for a total of three injections with an equivalent $0.75 \mathrm{mg} / \mathrm{kg}$ cisplatin and $0.18 \mathrm{mg} / \mathrm{kg}$ siRNAs 
where applicable. The mice were sacrificed when severe health problems were noticed. NCP-1 or NCP-1/ctrl siRNA alone showed no survival benefit over PBS (NCP-1 vs control, $P=0.3773, \mathrm{NCP}-1 / \mathrm{ctrl}$ siRNA vs control, $P=0.2568$ by one-way ANOVA). Although one mouse treated with PBS survived to Day 92 without showing obvious abnormal activity, a large tumor was observed growing directly on the right ovary (Figure S17). As shown in Figure 6A, NCP-1/siRNAs successfully eradicated all the tumors, leading to $100 \%$ survival for $>90$ days. 92 days after tumor inoculation, NCP-1/siRNAs treated mice were sacrificed with no tumors evident in their abdominal cavities (Figure S18).

To study tumor inhibition, $5 \times 10^{5}$ A2780/CDDP cells were i.p. injected into mice to establish the tumor model. Beginning 5 days after tumor inoculation, mice were treated at a cisplatin dose of $0.5 \mathrm{mg} / \mathrm{kg}$ and siRNA dose of $0.125 \mathrm{mg} / \mathrm{kg}$ every 3 days, for a total of three injections. All the mice were sacrificed on day 28 , and tumor growth was evaluated in terms of tumor nodule count and tumor weight. Neither PBS nor free cisplatin with siRNA treatments showed any anticancer efficacy. Treatment with NCP-1 completely suppressed tumor growth in 2 out of 6 mice with no tumors found at the end point, but tumor growth in the other 4 mice became highly aggressive. NCP-1/ctrl siRNA treatment also completely eradicated the tumors in 2 out of 5 mice, but tumor growth in the other 3 mice was aggressive. Treatment with NCP-1/siRNAs completely suppressed tumor growth in 4 out of 6 mice, while the remaining two mice each had 1-2 tumor nodules but no tumors growing directly on the ovaries. Compared to NCP-1, NCP-1/siRNAs treatment led to a significant decrease in tumor weight (443.8 mg for NCP-1 vs $15.5 \mathrm{mg}$ for NCP-1/siRNAs, Figure 6B) and tumor nodule count (Figure 6C, D).

\section{NCP-2/siRNAs with Further Enhanced Anticancer Efficacy against Resistant OCa}

Combination therapy with multiple chemotherapeutics successfully combats resistant cancers by promoting synergy of different drugs, increasing therapeutic target selectivity, and overcoming drug resistance by utilizing different mechanisms of action. Excited by the efficacy of cisplatin and siRNAs in our NCP-1/siRNAs platform, we developed a new DOPA-capped particle carrying cisplatin and gemcitabine, NCP-2. Since the cisplatin and gemcitabine combination is a standard of care for $\mathrm{OCa}$ in the clinic, NCP-2/siRNAs possess even greater potential for the treatment of challenging cancers. Particle synthesis was modified to incorporate gemcitabine monophosphate (GMP) into the core, followed by coating with DSPC, cholesterol, DSPE-PEG2k, and pooled DSPE-siRNA conjugates containing siERCC-1, si Bcl-2, and sisurvivin siRNAs. The Z-average, number-average, PDI, and zeta-potential of NCP-2/siRNAs were $84.1 \pm 0.9 \mathrm{~nm}, 48.8 \pm 3.2 \mathrm{~nm}, 0.170 \pm 0.004$, and $-3.43 \pm 0.06 \mathrm{mV}$ by DLS measurements (Table S3). The loading amounts of cisplatin, GMP, and siRNAs were $12.9 \pm 1.4 \mathrm{wt} \%$ by ICP-MS, $26.7 \pm 2.3 \mathrm{wt} \%$ by thermogravimetric analysis (TGA), and $4.9 \pm 0.3 \mathrm{wt} \%$ by fluorimetry, respectively (Figure S19). NCP-2/ siRNAs are observed to be monodispersed spherical nanoparticles by TEM (Figure 7A and Figure S20). The size of NCP-2 nanoparticles is stable in PBS containing $30 \mathrm{nM}$ bovine serum albumin (BSA) (Figure S21). The release of cisplatin and GMP from NCP-2 nanoparticles was slow in PBS but significantly promoted in PBS containing $5 \mathrm{mM}$ cysteine, which suggested their extracellular stability and efficient intracellular release (Figure S22). 
These physical properties of NCP-2 did not vary significantly from those of NCP-1 and NCP-1/siRNAs.

The pharmacokinetics and biodistribution profiles of NCP-2 were evaluated on CT26 tumorbearing BALB/c mice by i.v. injection (Figure 7B, C). Pt and GMP contents were quantified by ICP-MS and liquid chromatography mass spectrometry (LC-MS), respectively. The concentrations of drugs in the blood were fitted using two-compartment models. NCP-2 exhibited half-lives $\left(t_{1 / 2} \beta\right)$ of $18.5 \pm 5.2 \mathrm{~h}$ and $14.7 \pm 2.8 \mathrm{~h}$ for Pt and GMP, respectively. The peak tumor uptake was achieved at $10.4 \pm 0.8 \% \mathrm{ID} / \mathrm{g}$ at $24 \mathrm{~h}$ post injection. Similar to NCP-1 and NCP-1/siRNAs, NCP-2 particles are able to avoid uptake by MPS as evidenced by lower liver and kidney $\% \mathrm{ID} / \mathrm{g}$.

NCP-2/siRNAs demonstrated the unique endosomal escape mechanism of NCP-1/siRNAs with enhanced cytotoxic potential due to the addition of a second chemotherapeutic agent and a third siRNA. NCP-2/siRNAs retained efficient gene silencing as determined by ELISA assay (Figure S23) and increased cytotoxicity in SKOV-3 cells. NCP-2 and NCP-2/siRNAs dropped the cisplatin $\mathrm{IC}_{50}$ values by 3.7-fold and 11.8-fold, respectively, compared to free cisplatin (Figure S24, Table S4). In A2780/CDDP cells, the cisplatin IC $_{50}$ was more dramatically reduced, by 155.3 -fold and 530.5-fold for NCP-2 and NCP-2/siRNAs, respectively, compared to free cisplatin (Figure S25 and Table S4). For combination therapy, combination index (CI) values are used to evaluate the synergy between the two therapies, with CI values lower than, equal to, and greater than 1 indicating synergism, additivity, and antagonism, respectively. On A2780/CDDP and SKOV-3 cells, CI was 0.4-1.0 for NCP-2 against the monotherapeutic nanoparticles and free drug, and was further lowered to $\sim 0.2$ for NCP-2/siRNAs against the monotherapeutic nanoparticles and free drug (Figure S20-S21). This result indicated strong synergy among cisplatin, GMP, and siRNAs contributed to drastically enhanced anticancer efficacy against cisplatin-resistant OCa cells. This was further supported by the ability of NCP-2/siRNAs to more efficiently induce cell apoptosis compared to monotherapeutic nanoparticles, free drug, and NCP-2 in A2780/CDDP and SKOV-3 cells, as confirmed by Annexin V/PI analysis (Figure S26-S28 and Table S5).

By combining efficient gene silencing, enhanced cytotoxicity, strong synergy among cisplatin, GMP, and siRNAs, and favorable pharmacokinetics and biodistribution, NCP-2/ siRNAs showed unprecedented anticancer efficacy against a cisplatin-resistant SKOV-3 subcutaneous xenograft mouse model of OCa. Mice bearing SKOV-3 tumors $\left(\sim 150 \mathrm{~mm}^{3}\right)$ were treated with PBS, free cisplatin, and GMP with siRNAs, NCP-2, or NCP-2/siRNAs at $0.3 \mathrm{mg}$ cisplatin $/ \mathrm{kg}, 0.67 \mathrm{mg} \mathrm{GMP} / \mathrm{kg}$, and $0.15 \mathrm{mg}$ siRNAs $/ \mathrm{kg}$ every 5 days, for a total of two injections. As shown in Figure 7D, the free drug combination failed to inhibit tumor growth, while both NCP-2 and NCP-2/siRNAs treatment led to tumor regression after the first injection. NCP-2-treated mice showed rapid tumor regression followed by aggressive tumor regrowth 15 days later. In contrast, NCP-2/siRNAs completely eradicated the tumors, and the mice remained tumor-free for the 156 days until the completion of the experiment. 


\section{DISCUSSION}

Cancer is a complex disease-tumors often consist of mixed populations of malignant cells with a high degree of molecular and genetic heterogeneity, ${ }^{14,15}$ and cancers often develop different successive mutations to acquire resistance as they progress. Because combination therapy can increase the opportunity to address the significant issues of tumor heterogeneity and drug resistance, we developed NCP-1/ siRNAs, which combines the chemotherapy of cisplatin and the gene therapy of RNAi in a single platform. We demonstrated that delivering multiple siRNAs targeting distinct molecular signaling pathways can effectively overcome drug resistance in $\mathrm{OCa}$ and resensitize OCa to cisplatin treatment. We elaborated on our discovery by developing NCP-2/siRNAs, which carries two chemotherapeutics, cisplatin and gemcitabine, and three siRNAs, siERCC-1, siBCl-2, and sisurvivin. We found that it was even more efficient in overcoming drug resistance and leads to complete tumor eradication over a 156-day period.

The majority of the existing siRNA-containing nanotherapeutics in clinical trials are based on liposomes or polymers and target macrophages or liver diseases but cannot be used to effectively treat cancer. The literature contains few successful examples of in vivo siRNA delivery for cancer treatment using nanomaterials composed of polymers and cationic lipids or spherical nucleic acid nanoparticle conjugates. ${ }^{40}$ The development of siRNA carriers for cancer therapy has faced two main challenges: the opposing surface charge requirements for efficient endosomal escape (cationic) and long blood circulation (neutral) and the delicate balance between the affinity for siRNA binding and sufficient release at the sites of action. ${ }^{41-45}$ The most recognized endosomal escape mechanism, the proton sponge effect, requires cationic excipients in the carrier to help siRNA escape from the endosome after endocytosis. However, only nanoparticles with near neutral surface charge have demonstrated favorable pharmacokinetics and biodistribution after systemic injection, rendering the charged cationic excipient impossible. ${ }^{46-48}$ Furthermore, an siRNA delivery vehicle needs to have high binding affinity to siRNA in the extracellular environment to prevent nuclease degradation while achieving sufficient and rapid intracellular siRNA release in the cytoplasm to trigger gene silencing.

By combining an ideal size, cationic lipid-free formulation, and siRNA protection with a lipid shell, NCP-1/siRNAs maintain structural integrity in blood circulation. The prolonged blood circulation time and minimal MPS uptake allow the core-shell nanoparticles to take advantage of the EPR effect to preferentially localize in tumors. We noticed higher tumor uptake of NCP-1/siRNAs by i.p. injection, possibly due to efficient abdominal absorption and a mild peritoneal environment that causes less physical damage to the nanoparticle structure than the fast blood flow of i.v. injections.

We have previously demonstrated that the lipid shell gradually dissociates from the solid core of core-shell particles upon entering the cells. ${ }^{49}$ After shedding the lipid shell, the core is exposed to high concentrations of endogenous reducing agents to trigger cisplatin release via reductive cleavage of the metal-ligand bonds. Thus, NCP-1/siRNAs and NCP-2/siRNAs carrying high payloads of chemotherapeutic(s) and siRNAs release all drugs intracellularly, triggered by cysteine and glutathione concentrations that are higher than that of the 
extracellular environment. Inside the cells, the disulfide bond between DSPE and siRNAs is cleaved by the reducing agent, allowing the siRNA to be efficiently released from the lipid shell. When a cisplatin molecule is released, two $\mathrm{CO}_{2}$ molecules are generated inside the endosomes, changing their osmotic pressure and disrupting the endosome membrane, which facilitates endosomal escape of the siRNAs. Our built-in endosomal escape mechanism does not involve cationic lipids or polymers, thus allowing both NCP-1/siRNAs and NCP-2/ siRNAs to have near-neutral surface charges for prolonged systemic circulation. The efficient endosomal escape enabled by this novel mechanism potentiates gene silencing both in vitro and in vivo. We anticipate that this new endosomal escape mechanism can be applied to the design of other in vivo delivery systems for anticancer biotherapeutics, such as microRNA, antisense oligonucleotides, etc.

\section{CONCLUSION}

In summary, we developed novel self-assembled core-shell nanoparticles that combine two therapies - the chemotherapy of cisplatin or cisplatin and gemcitabine and the gene therapy of siRNA - into a single platform to allow for tumor eradication in cisplatin-resistant $\mathrm{OCa}$ mouse models by systemic injection. NCP-1/siRNAs and NCP-2/siRNAs have several distinct advantages over the other existing nanocarriers: (a) a highly modular synthesis that allows for the optimized loading of different drugs; (b) the ability to carry high loadings of both chemotherapeutic and siRNAs that release at the relevant sites of action; (c) a novel built-in endosomal escape mechanism that enables a cationic lipid-free siRNA delivery system; (d) prolonged systemic circulation and enhanced tumor accumulation after i.v. or i.p. injection; (e) combination therapy that effectively treats drug-resistant cancers; (f) effective tumor eradication by systemic administration in two cisplatin-resistant OCa mouse models. We believe these nanoparticles present a promising direction in nanomedicine by efficiently delivering siRNA delivery to cancers, incorporating multiple therapeutic modalities into a single vehicle, and providing a novel endosomal escape mechanism. On the basis of the numerous applications in cancer therapy of cisplatin and gemcitabine separately and in combination, we anticipate that these core-shell nanoparticles will have broad impacts on the treatment of challenging cancers.

\section{MATERIALS AND METHODS}

\section{Materials}

All of the starting materials were purchased from Sigma-Aldrich and Fisher (USA) unless otherwise noted and used without further purification. 1,2-dioleoyl-sn-glycero-3-phosphate (DOPA), 1,2-distearoyl-sn-glycero-3-phosphoethanolamine (DSPE), cholesterol, and 1,2distearoyl-sn-glycero-3-phosphoethanolamine- $N$-[amino-(polyethylene glycol)2000] (DSPE-PEG2k) were purchased from Avanti Polar Lipids (USA). The siRNA duplexes were supplied by Integrated DNA Technologies (USA) and dissolved in diethylpyrocarbonate (DEPC)-treated water before use. Survivin siRNA (sisurvivin), Bcl-2 siRNA (siBcl-2), ERCC-1 siRNA ( iERCC -1 ), and ctrl siRNA contained the antisense sequences of $5^{\prime}$ GGACCACCGCAUCUCUACAdTdT-3' ${ }^{\prime}$, 5'-UUCGGCAUUAGGCCUUCCGdTdG-3' ${ }^{\prime}$ ' ${ }^{\prime}$ GAGGCUGUGAGAUGGCAUATT- $3^{\prime}$, and $5^{\prime}$ - 
CGUUAAUCGCGUAUAAUACGCGUAT-3', respectively. A thiol modification was put on the $5^{\prime}$ end of the sense strand of each siRNA in order to avoid potential inhibition on the antisense strand. Alexa Fluor 647-labeled survivin siRNA with a thiol modification was used for the quantification and imaging of siRNAs.

Human ovarian cancer cell lines resistant to cisplatin SKOV-3 and A2780/CDDP were obtained from the American Type Culture Collection (Rockville, MD, USA) and Developmental Therapeutics Core, Northwestern University, respectively. The human ovarian cancer cell line sensitive to cisplatin A2780 was from Developmental Therapeutics Core, Northwestern University. SKOV-3 cells were cultured in McCoy's 5a medium containing 10\% fetal bovine serum (FBS). A2780 and A2780/CDDP cells were cultured in RPMI-1640 medium (Gibco, Grand Island, NY, USA) containing 10\% FBS. Raw 264.7 cells were cultured in DMEM medium containing 10\% FBS.

BALB/c and athymic female nude mice (6-8 weeks old, 20-25 g) were provided by Harlan Laboratories, Inc. (USA). The study protocol was reviewed and approved by the Institutional Animal Care and Use Committee (IACUC) at the University of Chicago.

\section{Synthesis of DSPE-siRNA Conjugate}

Succinimidyl 3-(2-pyridyldithio)propionate (SPDP, $21 \mathrm{mg}, 0.067 \mathrm{mmol}$ ) and 1,2-distearoylsn-glycero-3-phosphoethanolamine (DSPE, $50 \mathrm{mg}, 0.067 \mathrm{mmol}$ ) were dissolved in chloroform $(40 \mathrm{~mL})$ and refluxed under $\mathrm{N}_{2}$ in darkness for $48 \mathrm{~h}$. After removal of chloroform by rotary evaporation, the crude product was purified by diol-functionalized silica gel column chromatography. Yield: $40 \%{ }^{1}{ }^{\mathrm{H}} \mathrm{NMR}$ in $\mathrm{CDCl}_{3}: \delta 8.47(\mathrm{~d}, 1 \mathrm{H}) ; \delta 7.72(\mathrm{~m}$, $2 \mathrm{H}) ; \delta 7.14(\mathrm{~d}, 1 \mathrm{H}) ; \delta 5.25(\mathrm{~s}, 1 \mathrm{H}) ; \delta 4.38(\mathrm{~d}, 1 \mathrm{H}) ; \delta 4.17(\mathrm{~s}, 2 \mathrm{H}) ; \delta 3.99(\mathrm{t}, 4 \mathrm{H}) ; \delta 3.52(\mathrm{~s}, 1 \mathrm{H}) ;$ $\delta 3.03(\mathrm{t}, 2 \mathrm{H}) ; \delta 2.65(\mathrm{~s}, 2 \mathrm{H}) ; \delta 2.30(\mathrm{~d}, 2 \mathrm{H}) ; \delta 1.70(\mathrm{bs}, 1 \mathrm{H}) ; \delta 1.59(\mathrm{~s}, 2 \mathrm{H}) ; \delta 1.28(\mathrm{~s}, 60 \mathrm{H})$; $\delta 0.90(\mathrm{t}, 6 \mathrm{H})$. Thiolated siRNAs (IDT, USA) were conjugated to DSPE-SPDP to afford DSPE-siRNA conjugates via the disulfide bond.

\section{Preparation and Characterization of NCP-1/siRNAs}

DOPA-capped NCP-1 nanoparticles carrying a cisplatin prodrug were prepared according to our previous report. NCP-1/siRNAs was prepared by adding $10 \mu \mathrm{L}$ of aqueous solution of DSPE-siRNA (DSPE-siRNA/DOPA-coated NCP $=1: 16$ in weight ratio) and a THF solution $(80 \mu \mathrm{L})$ of cholesterol, DSPC (cholesterol/DOPC $=1: 2$ in molar ratio), $20 \mathrm{~mol} \%$ DSPEPEG2k, and DOPA-coated NCP to $500 \mu \mathrm{L}$ of $30 \%$ (v/v) ethanol/water at $50{ }^{\circ} \mathrm{C}$. The mixture was stirred at $1700 \mathrm{rpm}$ for $1 \mathrm{~min}$. THF and ethanol were completely evaporated, and the NCP-1/siRNAs solution was allowed to cool down to room temperature.

ICP-MS (Agilent 7700X, Agilent Technologies, USA) was utilized to analyze the Pt concentration of NCP to calculate cisplatin loadings. The amounts of siRNA loaded were quantified by Quant-iT RiboGreen RNA kit (Invitrogen, USA). The particle size and $\zeta$ potential of NCP-1/siRNAs in PBS were determined by Zetasizer (Nano ZS, Malvern, UK). Transmission electron microscopy (TEM, Tecnai Spirit, FEI, USA) was used to observe the morphology of NCP-1/siRNAs. 


\section{Preparation and Characterization of NCP-2/siRNAs}

DOPA-capped NCP-2 nanoparticles (DOPA-NCP-2) carrying a cisplatin prodrug and gemcitabine monophosphate (GMP) were synthesized by reverse microemulsion. Twentyfive $\mathrm{mg} / \mathrm{mL}$ cis, cis, trans-[Pt- $\left.\left(\mathrm{NH}_{3}\right)_{2} \mathrm{Cl}_{2}\left(\mathrm{OCONHP}(\mathrm{O})(\mathrm{OH})_{2}\right)_{2}\right](8.6 \mu \mathrm{mol}), 25 \mathrm{mg} / \mathrm{mL}$ GMP sodium salt solution $(14.6 \mu \mathrm{mol})$, and DOPA $(22 \mu \mathrm{mol})$ were added to a $5 \mathrm{~mL}$ aliquot of Triton-X-100 (0.3 M in 1.5 M hexanol/cyclohexane) solution to form a $W=7.4$ microemulsion. Another microemulsion of $5 \mathrm{~mL}$ Triton-X-100 (0.3 M, 1.5 M hexanol/ cyclohexane) containing $\mathrm{Zn}\left(\mathrm{NO}_{3}\right)_{2} \cdot 6 \mathrm{H}_{2} \mathrm{O}$ aq. (131 mmol) was also prepared. The two microemulsions were stirred vigorously for $15 \mathrm{~min}$ at room temperature. The two microemulsions were combined and stirred for an additional $30 \mathrm{~min}$ at room temperature. After the addition of $20 \mathrm{~mL}$ ethanol, NCP-2 particles were washed once with ethanol, once with $50 \%(\mathrm{v} / \mathrm{v})$ ethanol/cyclohexane, twice with $50 \%(\mathrm{v} / \mathrm{v})$ ethanol/THF, and redispersed in THF.

NCP-2/siRNAs was prepared by adding $10 \mu \mathrm{L}$ of aqueous solution of DSPE-siRNA conjugates (DSPE-siRNA/DOPA-NCP-2 $=1: 16$ in weight ratio) and a THF solution $(80 \mu \mathrm{L})$ of cholesterol, DSPC, DSPE-PEG2k (cholesterol:DSPC:DSPE-PEG2k $=1: 1: 0.75$ in molar ratio) and DOPA-NCP-2 to $500 \mu \mathrm{L}$ of $30 \%$ (v/v) ethanol/water at $60{ }^{\circ} \mathrm{C}$. The mixture was stirred at $1700 \mathrm{rpm}$ for $1 \mathrm{~min}$. THF and ethanol were completely evaporated and the NCP-2/ siRNAs solution was allowed to cool to room temperature.

ICP-MS (Agilent 7700X, Agilent Technologies, USA) was utilized to analyze the Pt concentration of NCP to calculate cisplatin loadings. siRNA loading amount was quantified by Quant-iT RiboGreen RNA kit (Invitrogen, USA). The particle size and $\zeta$ potential of NCP-2/siRNAs in PBS were determined by Zetasizer (Nano ZS, Malvern, UK). Transmission electron microscopy (TEM, Tecnai Spirit, FEI, USA) was used to observe the morphology of NCP-2/siRNAs.

\section{siRNA Protection and Release of NCP-1/siRNAs}

NCP-1/siRNAs, DSPE-siRNA conjugate, or free siRNA containing $10 \mu \mathrm{g}$ of siRNA was incubated with $20 \mu \mathrm{L}$ of fetal bovine serum (FBS) for 0.5, 2, 12, and $24 \mathrm{~h}$. After incubation, $0.5 \%(\mathrm{w} / \mathrm{v})$ Triton X-100 was added to the mixture to disassociate the lipid from the nanoparticle core. The mixture was centrifuged at $13000 \mathrm{rpm}$ for $15 \mathrm{~min}$, and the supernatant was subjected to electrophoresis to evaluate the siRNA integrity. The electrophoresis was run on a $2 \%(\mathrm{w} / \mathrm{v})$ agarose gel at $56 \mathrm{~V}$ for $1 \mathrm{~h}$. The intensity of each siRNA band on the gel was quantified by Image Lab software.

The siRNA release of NCP-1/siRNAs was evaluated in PBS supplemented with $4.5 \mu \mathrm{M}$ GSH (extracellular environment) or $10 \mathrm{mM}$ GSH (intracellular environment). NCP-1/ siRNAs containing $1 \mu \mathrm{g}$ of siRNA were incubated with $1 \mathrm{~mL}$ of PBS at $37^{\circ} \mathrm{C}$ with shaking. At predetermined time intervals, the suspension was centrifuged at $13000 \mathrm{rpm}$ for $10 \mathrm{~min}$, and $0.5 \mathrm{~mL}$ of the supernatant was quantified for the siRNA content by Quant-iT RiboGreen RNA kit. An equal volume of the release medium was added, and the precipitate was resuspended before further incubation. 


\section{Endosomal Escape Mechanism}

The cisplatin prodrug PtBp used to construct NCP-1 was dissolved in PBS followed by the addition of $5 \mathrm{mM}$ cysteine. Vigorous gas bubbling was observed while no gas generation was noted before adding cysteine. The gas generated from PtBp in the reducing environment was confirmed by gas chromatography (GC).

Alexa Fluor 647-labeled siRNA was used to prepare NCP-1/siRNAs. NCP-1/siRNAs were incubated with A2780/CDDP cells for 5, 10, 20, and 30 min, respectively. The cells were washed with PBS three times, stained with $100 \mathrm{nM}$ Lysotracker Green for $2 \mathrm{~h}$, fixed with $4 \%$ paraformaldehyde, and stained with $10 \mu \mathrm{g} / \mathrm{mL}$ DAPI for $20 \mathrm{~min}$. The cells were observed by CLSM. The colocalization of green fluorescence (Lysotracker Green-stained endosome/ lysosome) and red fluorescence (Alexa Fluor 647-labeled siRNA) was calculated by ImageJ.

\section{In Vitro Transfection of NCP-1/siRNAs}

SKOV-3 or A2780/CDDP cells were seeded at $2 \times 10^{5}$ cells per well in 24-well plates and further cultured for $24 \mathrm{~h}$. The culture media were replaced by $1 \mathrm{~mL}$ of prewarmed and fresh culture media containing $10 \%$ fetal bovine serum (FBS) prior to the experiment.

Nanoparticles were added to the cells at a siRNA dose of $6 \mathrm{nM}$, corresponding to a cisplatin dose of $0.32 \mu \mathrm{g}$ per well. Following incubation for $4 \mathrm{~h}$, the culture media were replaced by prewarmed and fresh culture media containing 10\% FBS and incubated an additional $20 \mathrm{~h}$. The supernatant of the culture media was collected to determine extracellular survivin production by ELISA (R\&D Systems, USA) following manufacturer's instructions. The cells were lysed, and the Bcl-2 amount in the lysate was quantified by ELISA (R\&D Systems, USA).

In addition, RNA was isolated from the transfected cells according to the Trizol reagent protocol (Invitrogen, USA), and cDNA was synthesized from $500 \mathrm{ng}$ of total RNA using PrimeScriptRT reagent kit (Takara Biotechnology Co. Ltd.) according to the manufacturer's instructions. Synthesized cDNA, forward and reverse primers, and the SYBR Premix Ex Taq (Takara Biotech. Co., Ltd.) were run on the CFX96 Real-Time PCR Detection System (BioRad, USA) to evaluate cellular Bcl-2 and survivin mRNA levels. Sequences of the primers used were designed with Primer Bank (Table S2). $\beta$-actin was used as an internal loading control.

\section{Cytotoxicity of NCP-1/siRNAs}

SKOV-3 cells were seeded at 5000 cells per well and A2780 and A2780/CDDP cells were seeded at 2500 cells per well in 96-well plates and further cultured for $24 \mathrm{~h}$. The culture media were replaced by $100 \mu \mathrm{L}$ of fresh culture media containing $10 \%$ FBS. Free drugs or nanoparticles were added to the cells at different cisplatin or siRNA doses. Following incubation for $72 \mathrm{~h}$, cell viability was determined by (3-(4,5-dimethylthiazol-2-yl)-5-(3carboxymethoxyphenyl)-2-(4-sulfophenyl)-2H-tetrazolium) (MTS) assay (Promega, USA) according to manufacturer's instructions. The concentrations of cisplatin and siRNA required to inhibit cell growth by $50 \%$ ( $\mathrm{IC}_{50}$ values) were calculated. 


\section{Pharmacokinetics and Biodistribution of NCP-1/siRNAs by Systemic Injection}

CT26 tumor-bearing BALB/c mice were intravenously or intraperitoneally injected with NCP-1/siRNAs at a cisplatin dose of $3 \mathrm{mg} / \mathrm{kg}$ equivalent to an siRNA dose of $0.75 \mathrm{mg} / \mathrm{kg}$. Mice were sacrificed at predetermined time points, and their blood, livers, spleens, lungs, kidneys, bladders, and tumors were harvested to determine Pt concentration by ICP-MS.

The pharmacokinetics of siRNA loaded into NCP-1/siRNAs was also evaluated. Three CT26 tumor-bearing mice were intravenously or intraperitoneally injected with NCP-1/siRNAs (Alexa Fluor 647-labeled siRNA was used) at a cisplatin dose of $3 \mathrm{mg} / \mathrm{kg}$, equivalent to an siRNA dose of $0.75 \mathrm{mg} / \mathrm{kg}$. Fifty microliters of blood were taken from orbital sinus of each mouse at predetermined time points. The blood was centrifuged at $12000 \mathrm{rpm}$ for $4 \mathrm{~min}$ to obtain the serum. The siRNA concentrations in the serum were determined by fluorimetry (excitation: $650 \mathrm{~nm}$; emission: $670 \mathrm{~nm}$ ).

\section{In Vivo Anticancer Efficacy of NCP-1/siRNAs in SKOV-3 Subcutaneous Xenograft Mouse Model}

Tumor-bearing mice were established by subcutaneous inoculation of SKOV-3 cell suspension $\left(5 \times 10^{6}\right.$ cells per mouse $)$ into the right flank region of 6-week-old athymic female nude mice. After tumor volumes reached approximately $100 \mathrm{~mm}^{3}$, the mice were randomly divided into 6 groups $(n=6)$ and given the following treatment: (1) PBS by i.v., (2) free cisplatin plus free pooled siRNA solution by i.v., (3) NCP-1 by i.v., (4) Zn control/ siRNAs by i.v., (5) NCP-1/siRNAs by i.v., and (6) NCP-1/siRNAs by i.p. at equivalent cisplatin doses of $0.75 \mathrm{mg} / \mathrm{kg}$ and siRNA doses of $0.18 \mathrm{mg} / \mathrm{kg}$. For groups (1)-(5), i.v. injections were administered every 3 days, for a total of four injections. For group (6), i.p. injections were administered every 3 days, for a total of two injections. Tumor volumes and body weights were monitored three times every week. Tumor volumes were calculated as follows: (width ${ }^{2} \times$ length) $/ 2$. All mice were sacrificed 14 days after the first treatment, and the excised tumors were weighed.

The mRNA expression levels and protein productions of Bcl-2 and survivin in the tumor were evaluated by Realtime-PCR. One hundred micrograms of tumor were homogenized in liquid nitrogen, and the RNA in the tumor tissues was extracted with the Trizol reagent. Intracellular Bcl-2 and survivin mRNA levels were thereafter monitored by Realtime-PCR.

TdT-mediated dUTP nick end labeling (TUNEL) reactions were performed on 5- $\mu \mathrm{m}$ frozen tumor sections using DNA Fragmentation Detection Kit (Life Technology, USA) according to the manufacturer's instructions and observed CLSM. DNA fragments in apoptotic cells were stained with fluorescein-conjugated deoxynucleotides (green) and the nuclei were stained with DAPI $(10 \mu \mathrm{g} / \mathrm{mL})$. The percentage of apoptotic cells was determined by the number ratio of TUNEL-positive cells/total cells by ImageJ.

Blood was collected at the end point of the in vivo antitumor efficacy experiment, and the serum was separated. The serum concentrations of TNF- $a$, IFN- $\gamma$, and IL- 6 were detected by ELISA (R\&D Systems, USA) to evaluate the immunogenic response evoked by NCP-1/ siRNAs. The plasma concentration of IgE was determined by ELISA (R\&D Systems, USA) to check the induction of hypersensitivity by NCP-1/siRNAs. No significant difference in the 
concentrations of TNF- $a$, IFN- $\gamma$, IL- 6 , and IgE between PBS and NCP-1/siRNAs were observed (Figure 5D).

Livers, lungs, spleens, and kidneys were also excised and embedded in OCT medium. Fivemicrometer frozen tissue sections were stained with hematoxylin and erosin (H\&E) and observed for toxicity with light microscopy.

\section{In Vivo Anticancer Efficacy in an Intraperitoneal A2780/CDPP Mouse Model}

To establish intraperitoneal tumors, A2780/CDDP cells were i.p. injected into female 6week-old athymic nude mice at a concentration of $2.5 \times 10^{6}$ cells per $\mathrm{ml}(200 \mu \mathrm{L}$ per injection). Mice were treated with PBS, NCP-1 (0.5 mg cisplatin/ $/ \mathrm{kg})$, and NCP-1/siRNAs $(0.5 \mathrm{mg}$ cisplatin $/ \mathrm{kg}, 0.125 \mathrm{mg}$ siRNA/kg) via i.p. injection every 3 days beginning 5 days after tumor cell injection, for a total of three injections. The body weights of the mice was measured on Day 0 and monitored daily after the first drug administration. The mice were sacrificed on Day 28 and tumor growth in terms of tumor nodule count and tumor weight was evaluated.

To evaluate the survival benefit of NCP-1/siRNAs, A2780/CDDP cells were i.p. injected into female 6-week-old athymic nude mice at a concentration of $5 \times 10^{5}$ cells per $\mathrm{ml}(200 \mu \mathrm{L}$ per injection). Mice were treated with PBS, NCP-1 (0.5 mg cisplatin/ $/ \mathrm{kg})$, and NCP-1/siRNAs $(0.5 \mathrm{mg}$ cisplatin $/ \mathrm{kg}, 0.125 \mathrm{mg}$ siRNA/kg) via i.p. injection every 3 days beginning on Day 5 following tumor cell injection, for a total of three injections. The body weights of the mice were measured on Day 0 and monitored daily after the first drug administration. The mice were sacrificed when severe health problems were noticed in compliance with the IACUC protocol. The study ended on Day 92.

\section{In Vivo Anticancer Efficacy of NCP-2/siRNAs in a SKOV-3 Subcutaneous Xenograft Mouse Model}

Tumor-bearing mice were established by subcutaneous inoculations of SKOV-3 cell suspension $\left(5 \times 10^{6}\right.$ cells per mouse $)$ into the right flank region of 6-week-old athymic female nude mice. After tumor volumes reached approximately $150 \mathrm{~mm}^{3}$, the mice were randomly divided into 4 groups ( $n=6$ for PBS, free drugs, and NCP-2/siRNAs; $\mathrm{n}=3$ for NCP-2) and given the following treatments: (1) PBS by i.p., (2) free cisplatin + GMP + siRNAs by i.p., (3) NCP-2 by i.p., and (4) NCP-2/siRNAs by i.p. at equivalent cisplatin doses of $0.3 \mathrm{mg} / \mathrm{kg}$, GMP doses of $0.67 \mathrm{mg} / \mathrm{kg}$, and siRNA doses of $0.15 \mathrm{mg} / \mathrm{kg}$ on Day 0 and Day 5 , for a total of two injections. Tumor volumes and body weights were monitored three times a week. Tumor volumes were calculated as follows: (width ${ }^{2} \times$ length)/2. Mice were sacrificed when tumor volumes reached $2 \mathrm{~cm}^{3}$, or 138 days after the first treatment.

\section{Supplementary Material}

Refer to Web version on PubMed Central for supplementary material. 


\section{Acknowledgments}

We thank Dr. Demin Liu, Mr. Alexander Chen, and Ms. Kristine Ma for experimental help and Dr. Gini Fleming for helpful discussion. We acknowledge NIH (UO1-CA198989) and the University of Chicago Medicine Comprehensive Cancer Center (NIH CCSG: P30 CA014599) for funding support.

\section{References}

1. Menon U, Gentry-Maharaj A, Griffin M. Gynecol Oncol. 2014; 132:490. [PubMed: 24316306]

2. Coleman RL, Monk BJ, Sood AK, Herzog TJ. Nat Rev Clin Oncol. 2013; 10:211. [PubMed: 23381004]

3. Vaughan S, Coward JI, Bast RC, Berchuck A, Berek JS, Brenton JD, Coukos G, Crum CC, Drapkin R, Etemadmoghadam D, Friedlander M, Gabra H, Kaye SB, Lord CJ, Lengyel E, Levine DA, McNeish IA, Menon U, Mills GB, Nephew KP, Oza AM, Sood AK, Stronach EA, Walczak H, Bowtell DD, Balkwill FR. Nat Rev Cancer. 2011; 11:719. [PubMed: 21941283]

4. Roberts D, Schick J, Conway S, Biade S, Laub PB, Stevenson JP, Hamilton TC, O’Dwyer PJ, Johnson SW. Br J Cancer. 2005; 92:1149. [PubMed: 15726096]

5. Kelland L. Nat Rev Cancer. 2007; 7:573. [PubMed: 17625587]

6. Ushijima K. J Oncol. 2010; 2010:497429. [PubMed: 20066162]

7. Muggia F. Gynecol Oncol. 2009; 112:275. [PubMed: 18977023]

8. Davis A, Tinker AV, Friedlander M. Gynecol Oncol. 2014; 133:624. [PubMed: 24607285]

9. Diaz-Padilla I, Malpica AL, Minig L, Chiva LM, Gershenson DM, Gonzalez-Martin A. Gynecol Oncol. 2012; 126:279. [PubMed: 22555104]

10. Nieman KM, Kenny HA, Penicka CV, Ladanyi A, Buell-Gutbrod R, Zillhardt MR, Romero IL, Carey MS, Mills GB, Hotamisligil GS, Yamada SD, Peter ME, Gwin K, Lengyel E. Nat Med. 2011; 17:1498. [PubMed: 22037646]

11. Agarwal R, Kaye SB. Nat Rev Cancer. 2003; 3:502. [PubMed: 12835670]

12. van der Zee AG, Hollema HH, de Bruijn HW, Willemse PH, Boonstra H, Mulder NH, Aalders JG, de Vries EG. Gynecol Oncol. 1995; 58:165. [PubMed: 7622101]

13. Markman JL, Rekechenetskiy A, Holler E, Ljubimova JY. Adv Drug Delivery Rev. 2013; 65:1866.

14. Igney FH, Krammer PH. Nat Rev Cancer. 2002; 2:277. [PubMed: 12001989]

15. Gottesman MM. Annu Rev Med. 2002; 53:615. [PubMed: 11818492]

16. Lin QY, Jin CS, Huang H, Ding LL, Zhang ZH, Chen J, Zheng G. Small. 2014; 10:3072. [PubMed: 24706435]

17. Zhang J, Li X, Huang L. J Controlled Release. 2014; 190:440.

18. Chen W, Yang L. Methods Mol Biol. 2016; 1372:49. [PubMed: 26530914]

19. Cho YS, Lee GY, Sajja HK, Qian WP, Cao ZH, He WL, Karna P, Chen XY, Mao H, Wang YA, Yang L. Small. 2013; 9:1964. [PubMed: 23292656]

20. Talekar M, Ouyang Q, Goldberg MS, Amiji MM. Mol Cancer Ther. 2015; 14:1521. [PubMed: 25964202]

21. Yang XQ, Lyer AK, Singh A, Choy E, Hornicek FJ, Amiji MM, Duan ZF. Sci Rep. 2015; 5:8509. [PubMed: 25687880]

22. Fire A, Xu SQ, Montgomery MK, Kostas SA, Driver SE, Mello CC. Nature. 1998; 391:806. [PubMed: 9486653]

23. Giljohann DA, Seferos DS, Prigodich AE, Patel PC, Mirkin CA. J Am Chem Soc. 2009; 131:2072. [PubMed: 19170493]

24. Tebes SJ, Kruk PA. Gynecol Oncol. 2005; 99:736. [PubMed: 16194565]

25. Pecot CV, Calin GA, Coleman RL, Lopez-Berestein G, Sood AK. Nat Rev Cancer. 2011; 11:59. [PubMed: 21160526]

26. Ozcan G, Ozpolat B, Coleman RL, Sood AK, Lopez-Berestein G. Adv Drug Delivery Rev. 2015; 87:108.

J Am Chem Soc. Author manuscript; available in PMC 2017 November 03. 
27. Caster JM, Sethi M, Kowalczyk S, Wang E, Tian X, Hyder SN, Wagner KT, Zhang YA, Kapadia C, Au KM, Wang AZ. Nanoscale. 2015; 7:2805. [PubMed: 25584654]

28. Min YZ, Caster JM, Eblan MJ, Wang AZ. Chem Rev. 2015; 115:11147. [PubMed: 26088284]

29. Huynh E, Zheng G. Nanomedicine. 2015; 10:1993. [PubMed: 26096565]

30. Miao L, Wang YH, Lin CM, Xiong Y, Chen NH, Zhang L, Kim WY, Huang L. J Controlled Release. 2015; 217:27.

31. Ling D, Xia H, Park W, Hackett MJ, Song C, Na K, Hui KM, Hyeon T. ACS Nano. 2014; 8:8027. [PubMed: 25093274]

32. Patil R, Gangalum PR, Wagner S, Portilla-Arias J, Ding H, Rekechenetskiy A, Konda B, Inoue S, Black KL, Ljubimova JY, Holler E. Macromol Biosci. 2015; 15:1212. [PubMed: 26036700]

33. Oberoi HS, Nukolova NV, Kabanov AV, Bronich TK. Adv Drug Delivery Rev. 2013; 65:1667.

34. Davis ME, Chen Z, Shin DM. Nat Rev Drug Discovery. 2008; 7:771. [PubMed: 18758474]

35. Petros RA, DeSimone JM. Nat Rev Drug Discovery. 2010; 9:615. [PubMed: 20616808]

36. Ling D, Park W, Park SJ, Lu Y, Kim KS, Hackett MJ, Kim BH, Yim H, Jeon YS, Na K, Hyeon T. J Am Chem Soc. 2014; 136:5647. [PubMed: 24689550]

37. Sun T, Wang Y, Xu J, Zhao X, Vangveravong S, Mach RH, Xia Y. Adv Healthcare Mater. 2014; 3:1283.

38. He C, Liu D, Lin W. Biomaterials. 2015; 36:124. [PubMed: 25315138]

39. Liu D, Poon C, Lu K, He C, Lin W. Nat Commun. 2014; 5:4182. [PubMed: 24964370]

40. Jensen SA, Day ES, Ko CH, Hurley LA, Luciano JP, Kouri FM, Merkel TJ, Luthi AJ, Patel PC, Cutler JI, Daniel WL, Scott AW, Rotz MW, Meade TJ, Giljohann DA, Mirkin CA, Stegh AH. Sci Transl Med. 2013; 5:209ra152.

41. Varkouhi AK, Scholte M, Storm G, Haisma HJ. J Controlled Release. 2011; 151:220.

42. Dominska M, Dykxhoorn DM. J Cell Sci. 2010; 123:1183. [PubMed: 20356929]

43. Gilleron J, Querbes W, Zeigerer A, Borodovsky A, Marsico G, Schubert U, Manygoats K, Seifert S, Andree C, Stoter M, Epstein-Barash H, Zhang L, Koteliansky V, Fitzgerald K, Fava E, Bickle M, Kalaidzidis Y, Akinc A, Maier M, Zerial M. Nat Biotechnol. 2013; 31:638. [PubMed: 23792630]

44. Miele E, Spinelli GP, Di Fabrizio E, Ferretti E, Tomao S, Gulino A. Int J Nanomed. 2012; 7:3637. 45. Castanotto D, Rossi JJ. Nature. 2009; 457:426. [PubMed: 19158789]

46. Albanese A, Tang PS, Chan WCW. Annu Rev Biomed Eng. 2012; 14:1. [PubMed: 22524388]

47. Chou LYT, Ming K, Chan WCW. Chem Soc Rev. 2011; 40:233. [PubMed: 20886124]

48. Li SD, Huang L. Mol Pharmaceutics. 2008; 5:496.

49. He C, Liu D, Lin W. ACS Nano. 2015; 9:991. [PubMed: 25559017]

J Am Chem Soc. Author manuscript; available in PMC 2017 November 03. 


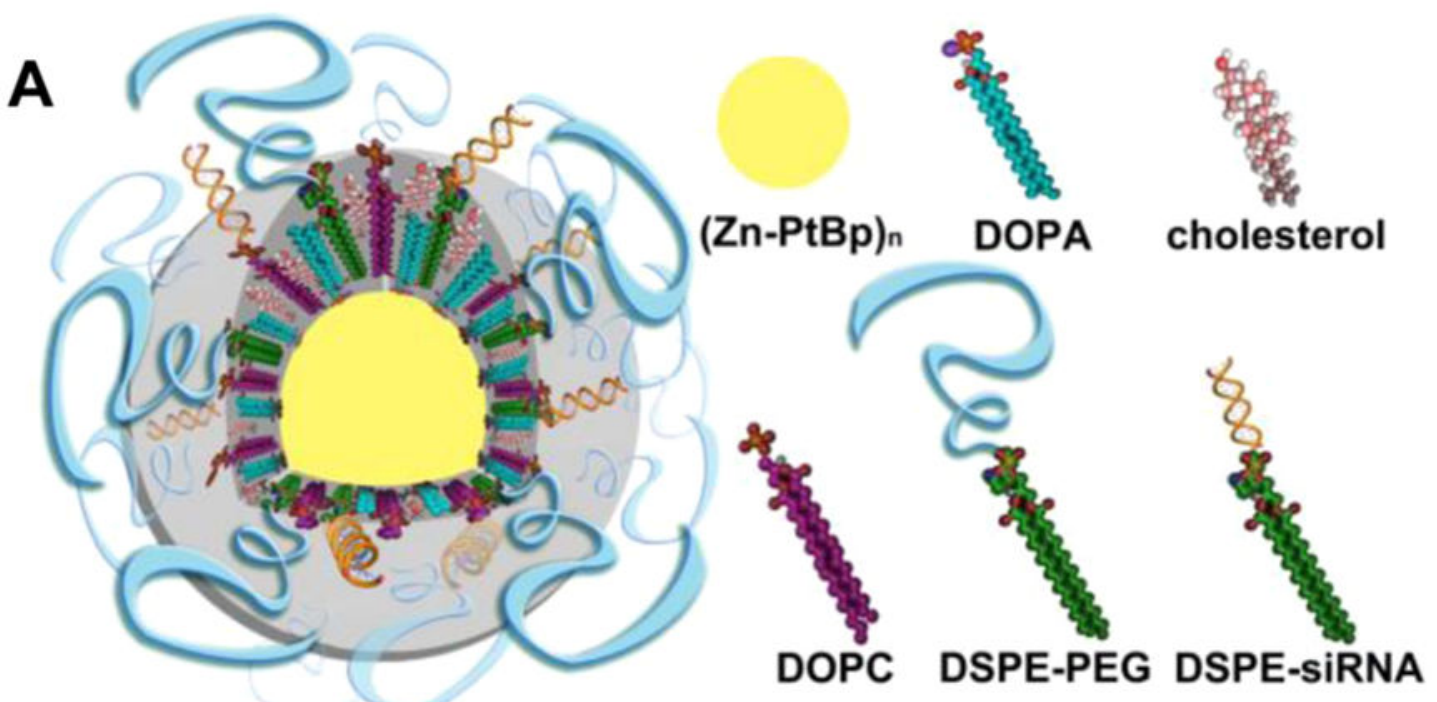

B
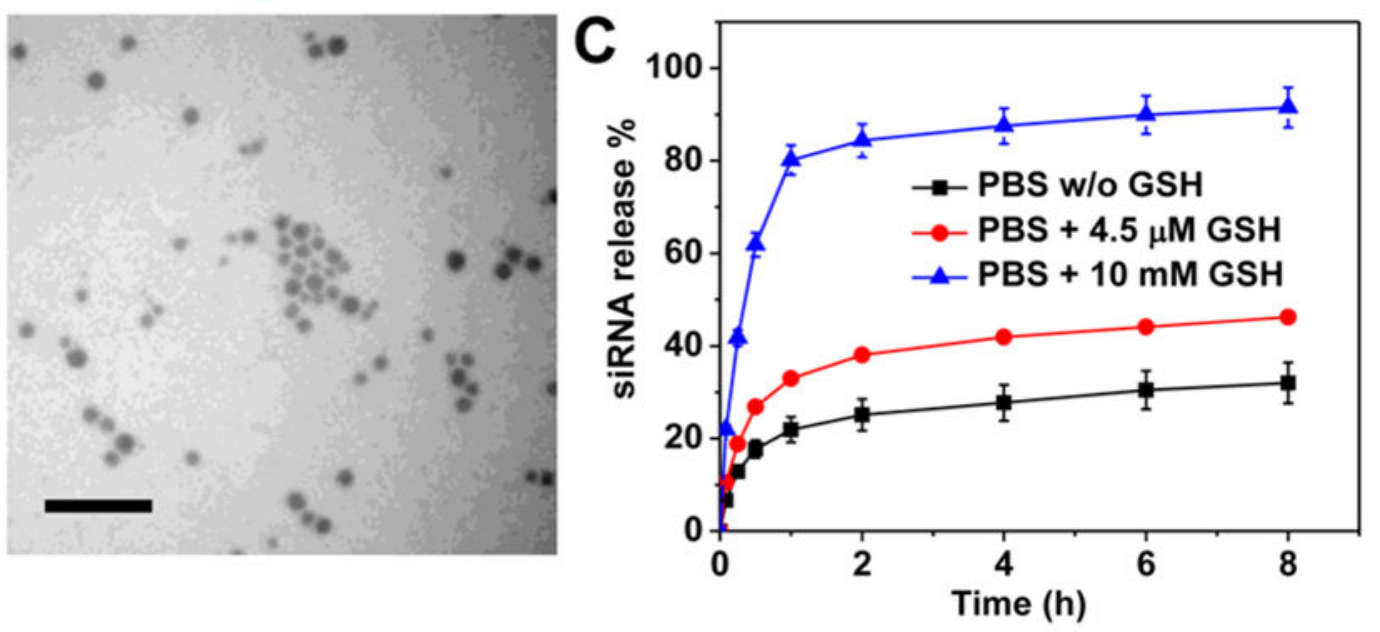

D
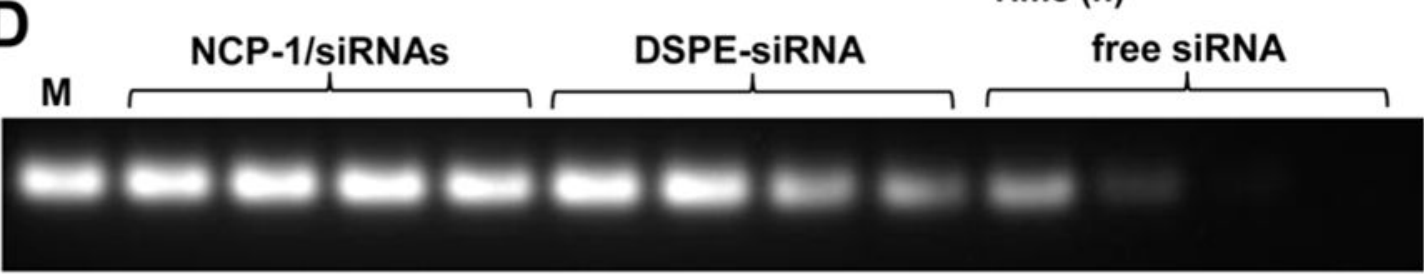

Time (h)

(h) 0.5

Figure 1.

Preparation and characterization of NCP-1/siRNAs. (A) Schematic representation of NCP-1/ siRNAs carrying cisplatin in the solid core and siRNAs in the lipid shell. (B) TEM image of NCP-1/siRNAs showing the spherical and monodispersed nanostructure. Bar $=100 \mathrm{~nm}$. (C) siRNA release from NCP-1/siRNAs in the presence or absence of reducing agents. (D) Improved siRNA stability in serum of NCP-1/siRNAs compared to free siRNA and DSPEsiRNA conjugate as evaluated by electrophoresis ( $2 \%$ agarose gel). "M" stands for untreated siRNA marker. 
<smiles>N[P+](Cl)(OC(=O)NP(=O)(O)O)P(N)(N)(Cl)OC(=O)NP(=O)(O)O</smiles><smiles>CC(N)(CC(=O)O)[P+](C)(C)Cl</smiles><smiles>[B]</smiles>
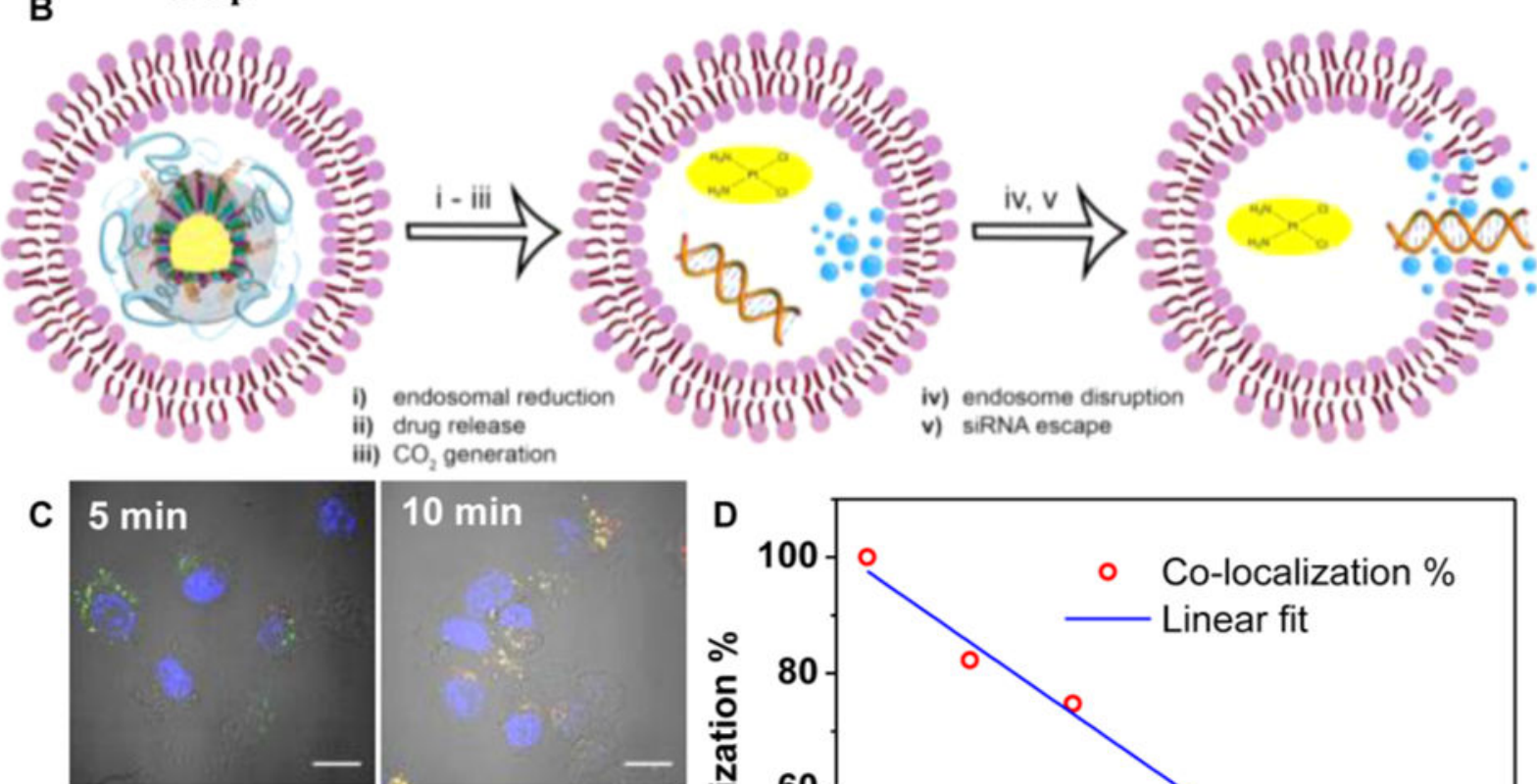

iv) endosome discupt
v) siRNA escape
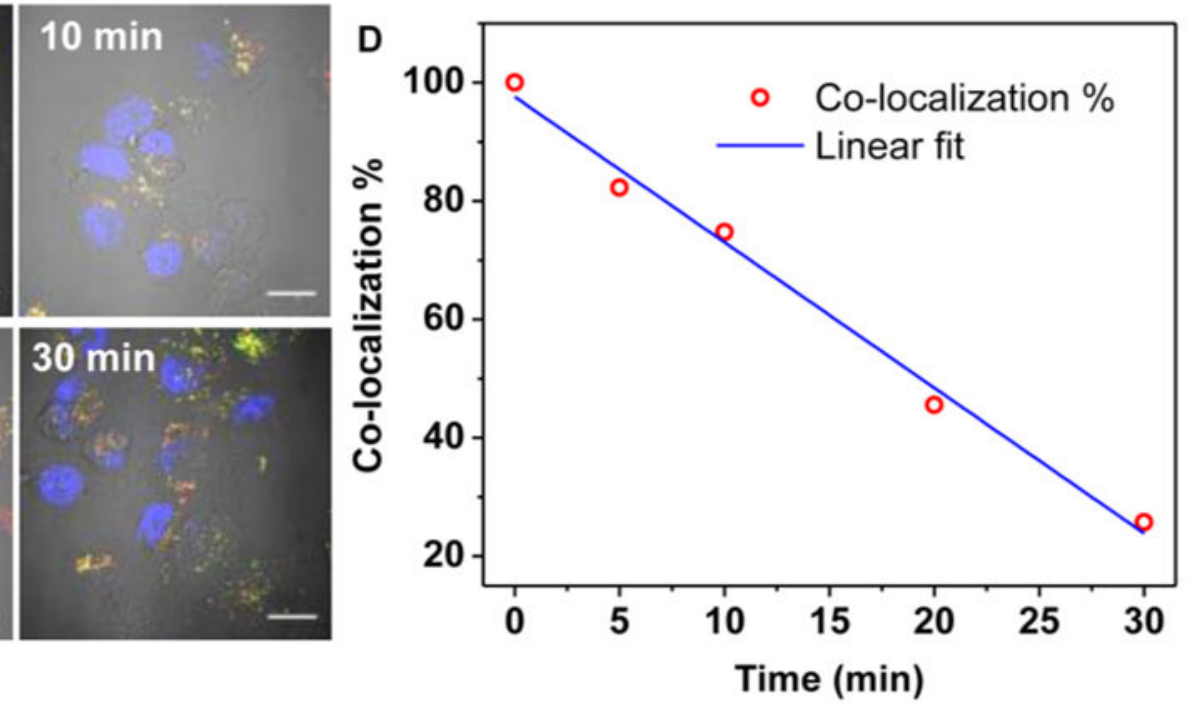

Figure 2.

Novel endosomal escape mechanism. (A) Scheme showing the $\mathrm{CO}_{2}$ generation of PtBp in the reducing environment. (B) Schematic showing the endosomal escape of NCP-1/siRNAs. (C) Time-dependent endosomal escape of NCP-1/siRNAs (Alexa Fluor647-labeled, red fluorescence) in SKOV-3 cells. Endosomes and nuclei were stained with Lysotracker Green (green fluorescence) and DAPI (blue fluorescence), respectively. Bar $=20 \mu \mathrm{m}$. (D) Percent colocalization of siRNA and endosome quantified by ImageJ based on (C). 

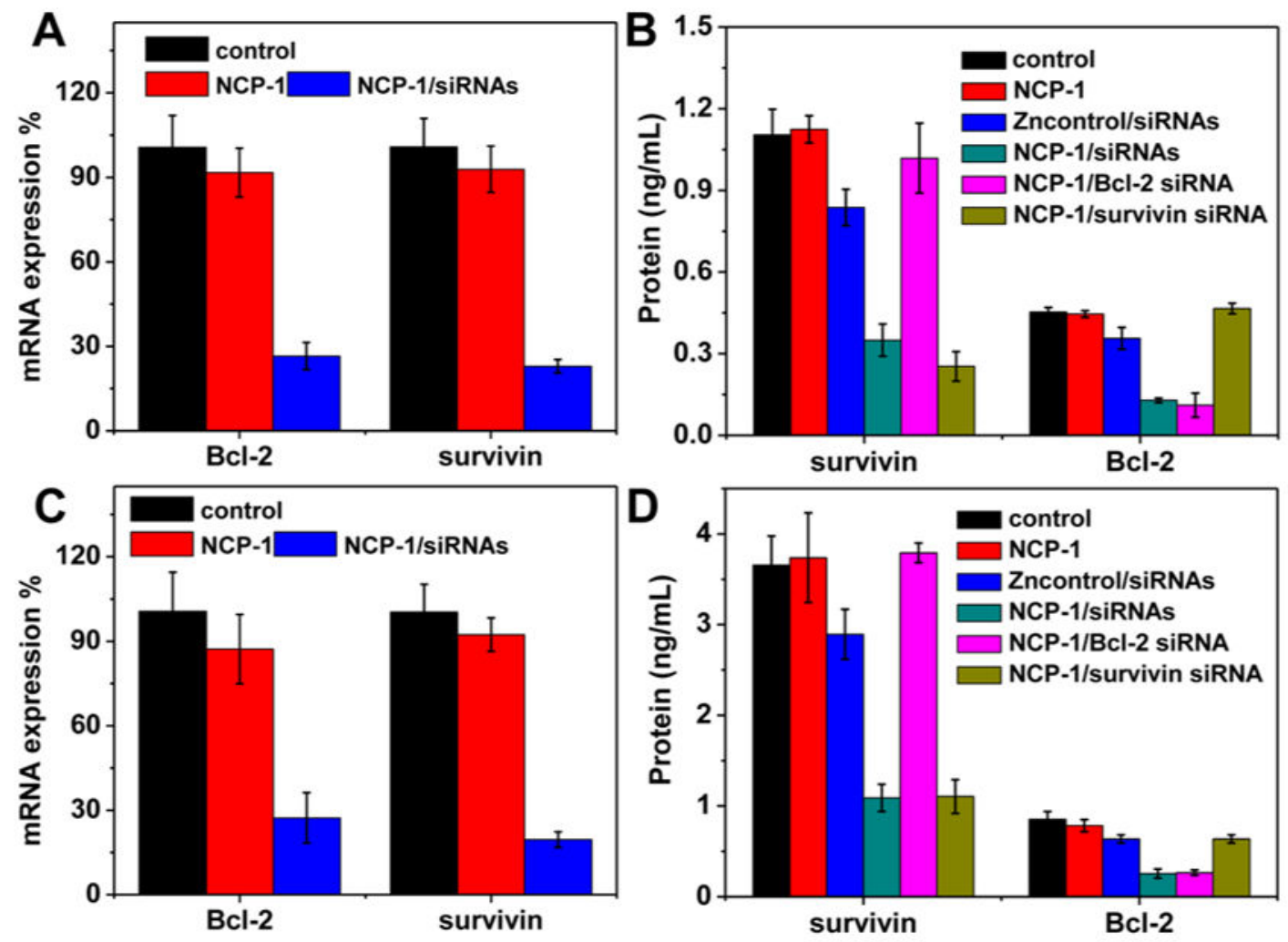

Figure 3.

Efficient in vitro gene silencing. mRNA expression and protein production of $\mathrm{Bcl}-2$ and survivin in cisplatin-resistant OCa cells (A, B for SKOV-3 and C, D for A2780/CDDP) transfected with NCP-1/siRNAs at an siRNA concentration of $6 \mathrm{nM}(n=3)$. 

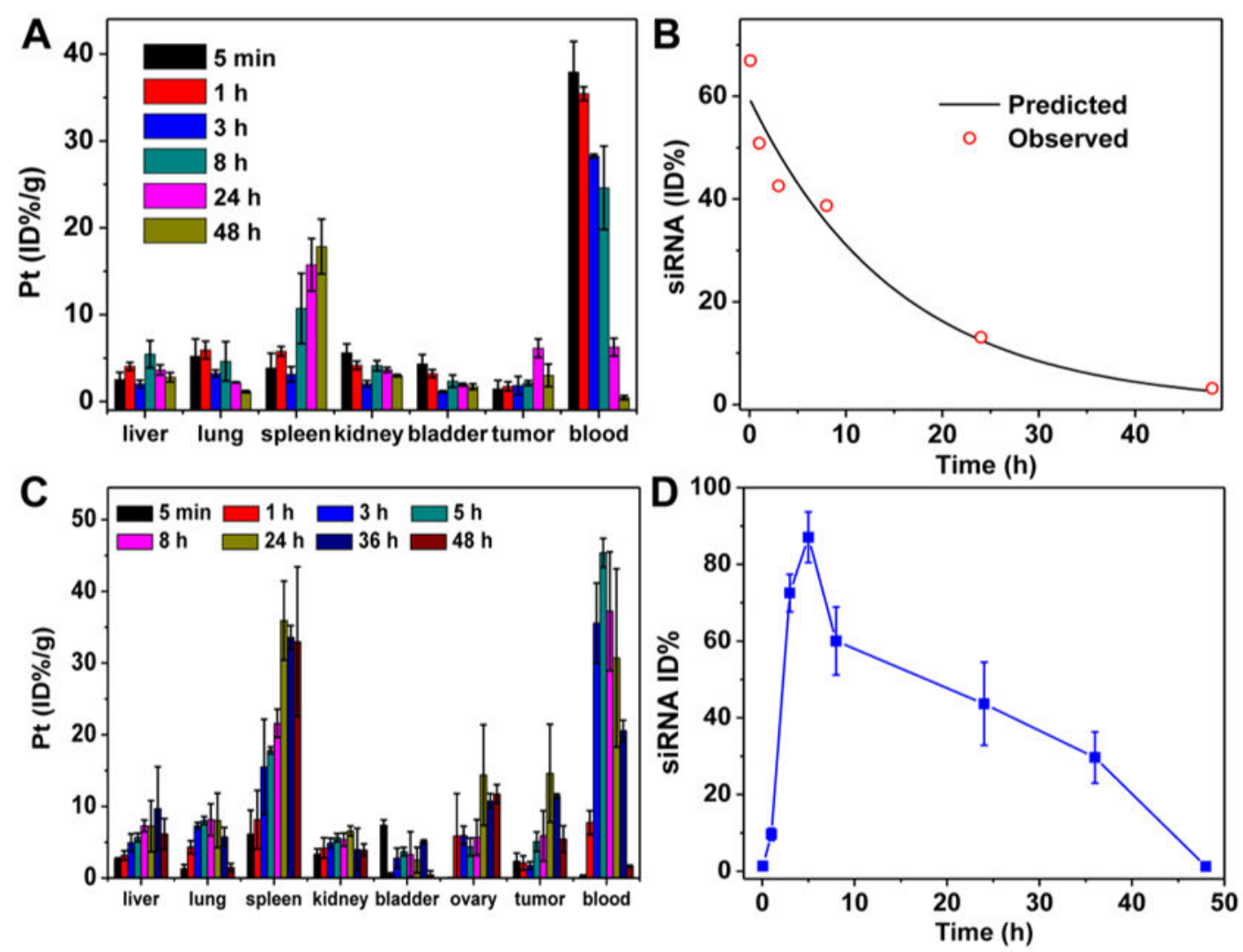

Figure 4.

Pharmacokinetics and tissue distributions of NCP-1/siRNAs by systemic injections. Tissue distributions of Pt at different time points after i.v. (A) or i.p. (C) injection of NCP-1/ siRNAs. Time-dependent siRNA concentrations in blood after i.v. (B) or i.p. (D) injection of NCP-1/siRNAs. The one-compartment model was used to fit the observed data in (B). Data are expressed as means $\pm \mathrm{SD}(N=3)$. 

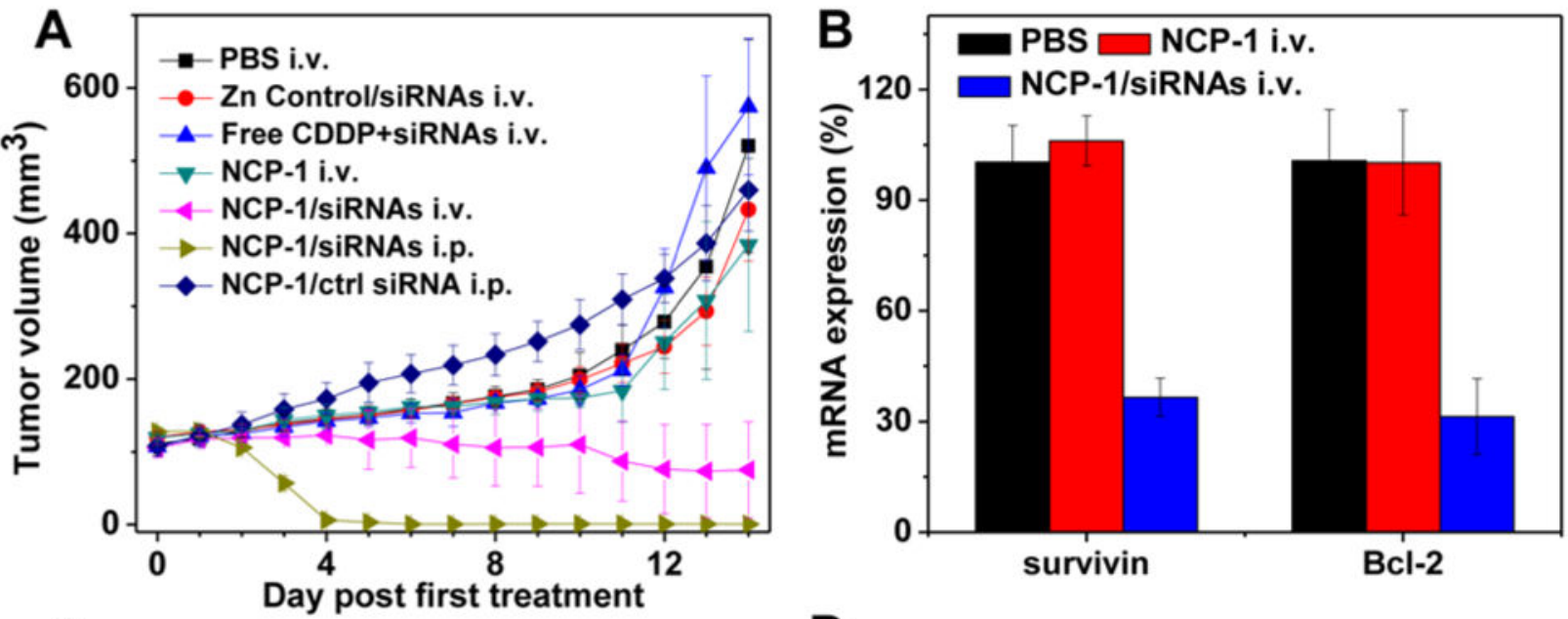

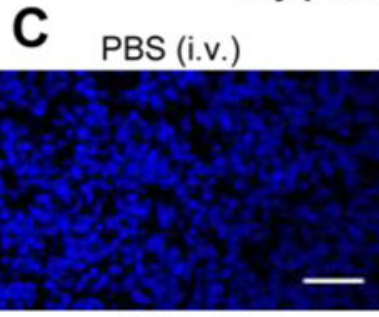

Free cis+siRNAs (i.v.) NCP-1 (i.v.)
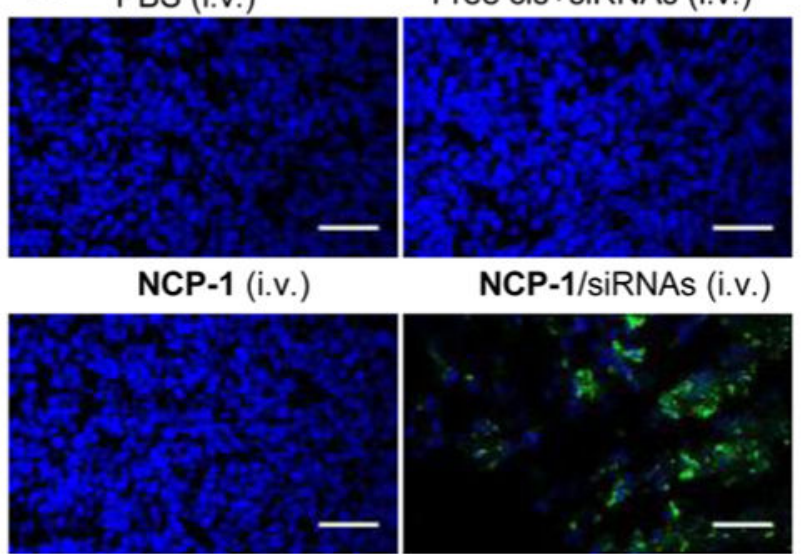

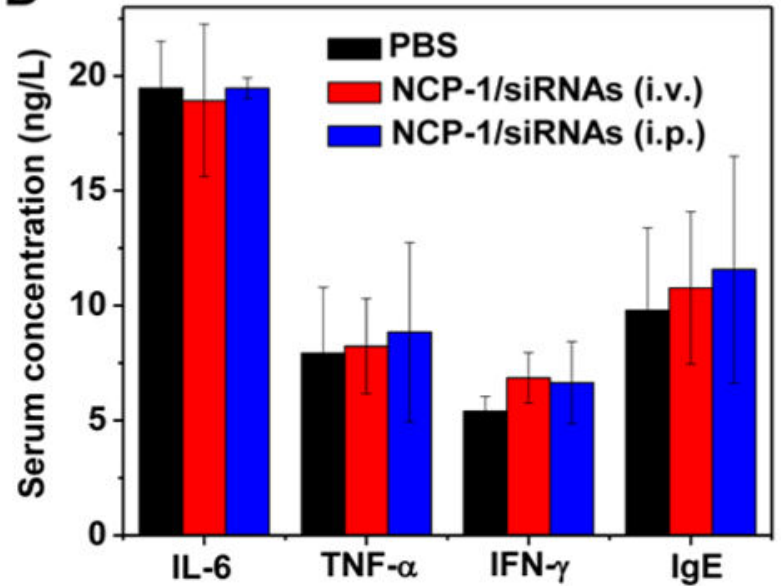

Figure 5.

In vivo anticancer effects of NCP-1/siRNAs on a SKOV-3 subcutaneous xenograft mouse model. (A) Tumor growth curves of the mice receiving i.p. or i.v. injections of NCP-1 ( $n=5$ for NCP-1/ctrl siRNA and $n=6$ for all the other groups). For i.v. injections, mice received treatments every 3 days for a total of three injections at an equivalent cisplatin dose of 0.75 $\mathrm{mg} / \mathrm{kg}$ and siRNA dose of $0.18 \mathrm{mg} / \mathrm{kg}$. For i.p. injections, mice received treatments every 3 days, for a total of two injections at an equivalent cisplatin dose of $0.75 \mathrm{mg} / \mathrm{kg}$ and siRNA dose of $0.18 \mathrm{mg} / \mathrm{kg}$. (B) The mRNA expression levels of Bcl-2 and survivin significantly decreased in the tumors of mice receiving an i.v. injection of NCP-1/siRNAs $(n=3)$. (C) Representative CLSM images of TUNEL assays of tumor tissues. DNA fragments in apoptotic cells were stained with fluorescein-conjugated deoxynucleotides (green), and the nuclei were stained with DAPI (blue). Bar represents $50 \mu \mathrm{m}$. (D) TNF- $a$, IL-6, IFN- $\gamma$, and IgE concentrations in the serum of SKOV-3 tumor-bearing mice receiving i.v. or i.p. injections of NCP-1/siRNAs were determined by ELISA. 

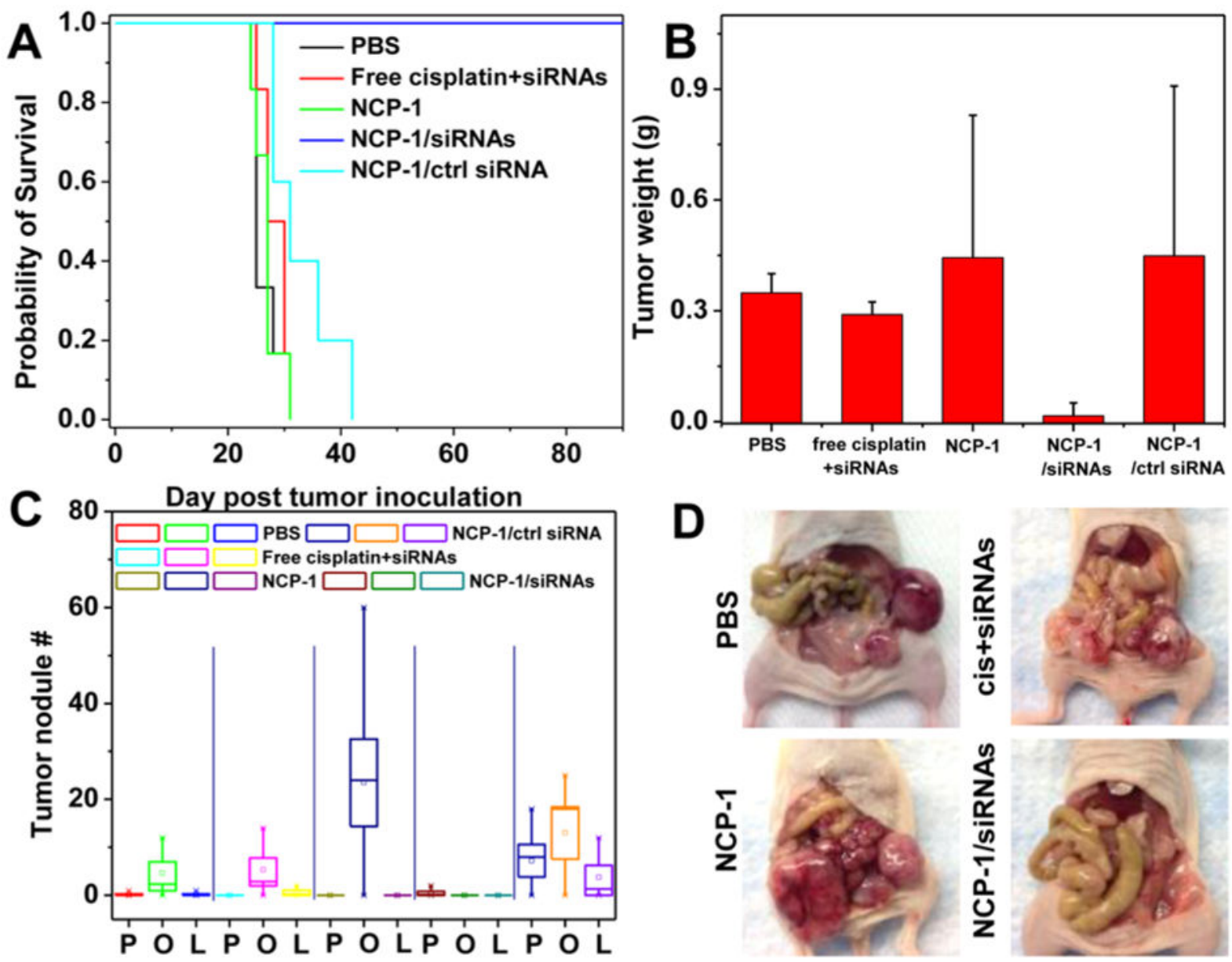

Figure 6.

In vivo anticancer efficacy of NCP-1/siRNAs in a cisplatin-resistant A2780/CDPP intraperitoneal xenograft mouse model. (A) Survival curves of mice receiving i.p. injections of nanoparticles at a cisplatin dose of $0.5 \mathrm{mg} / \mathrm{kg}$ and siRNA dose of $0.125 \mathrm{mg} / \mathrm{kg}$ every 3 days for a total of three injections ( $n=5$ for NCP-1/ctrl siRNA and $n=6$ for all the other groups). Tumor inhibition: tumor weight (B), tumor nodule count (C), and representative peritoneal view (D) of mice receiving i.p. injections of nanoparticles at a cisplatin dose of $0.5 \mathrm{mg} / \mathrm{kg}$ and siRNA dose of $0.125 \mathrm{mg} / \mathrm{kg}$ every 3 days for a total of three injections and sacrificed on Day 28 post tumor inoculation ( $n=5$ for NCP-1/ctrl siRNA and $n=6$ for all the other groups). "P", "O", and "L" in the legend of (C) refer to peritoneum, omentum, and liver, respectively. 

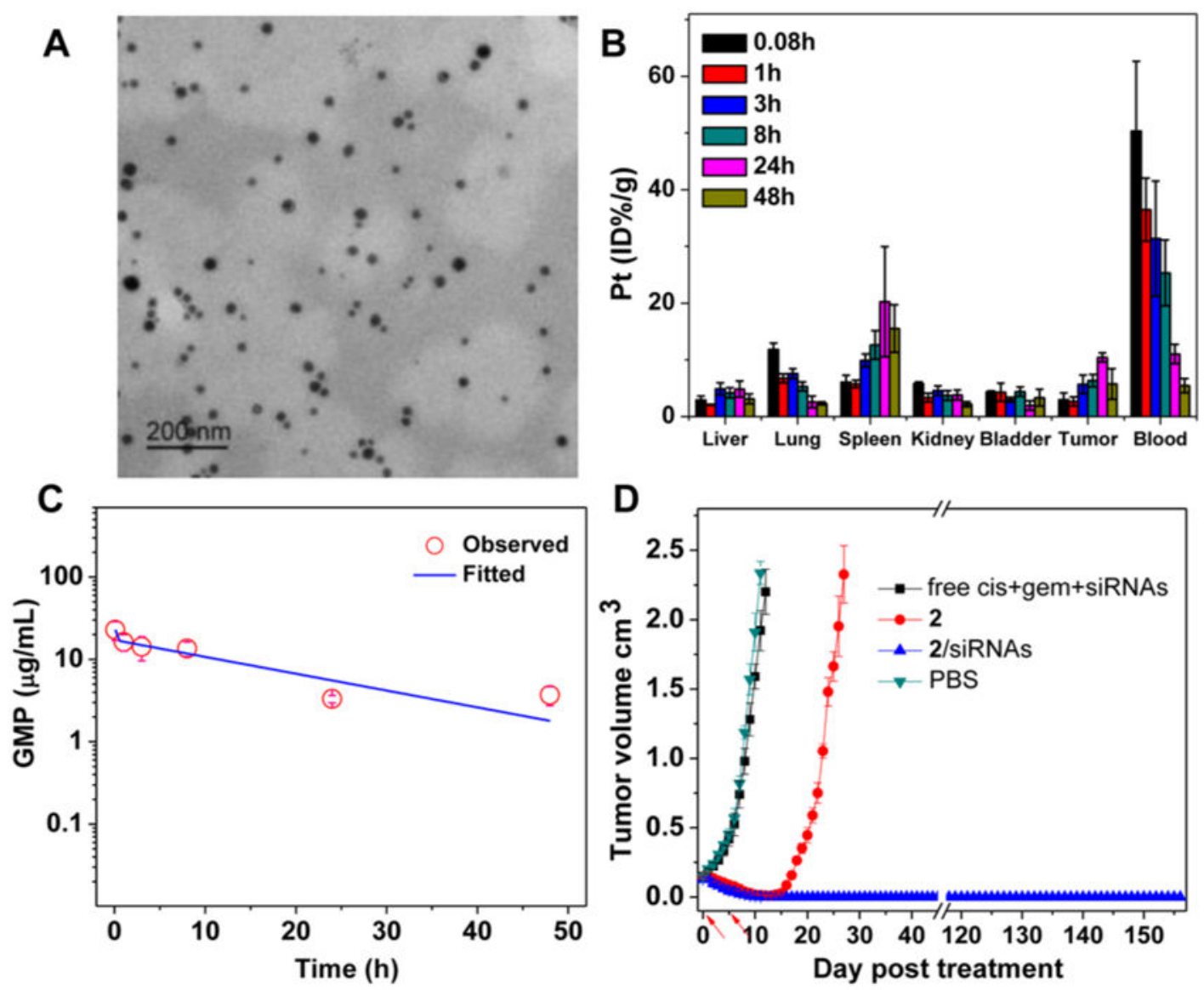

Figure 7.

Characterization, pharmacokinetics, biodistribution, and in vivo anticancer efficacy of NCP-2/siRNAs. (A) TEM showing the monodispersed and spherical morphology of NCP-2/ siRNAs. Pharmacokinetics and biodistribution of NCP-2 in terms of Pt by ICP-MS (B) and GMP by LC-MS (C). (D) Anticancer efficacy of NCP-2/siRNAs against SKOV-3 subcutaneous xenografts. Free drug combination or nanoparticles were intraperitoneally injected at $0.3 \mathrm{mg}$ cisplatin/ $\mathrm{kg}, 0.67 \mathrm{mg}$ GMP/kg, and $0.15 \mathrm{mg}$ siRNAs $/ \mathrm{kg}$ on Day 0 and Day 5 for a total of two injections. 


\section{Table 1}

Cisplatin $\mathrm{IC}_{50}$ Values of Free Cisplatin+siRNAs, NCP-1, and NCP-1/siRNAs in SKOV-3, A2780, and A2780/ CDDP Cells after $72 \mathrm{~h}$ Incubation

\begin{tabular}{lccc}
\hline & SKOV-3 $(\boldsymbol{\mu M})$ & A2780 $(\boldsymbol{\mu} \mathbf{M})$ & A2780/CDDP $(\boldsymbol{\mu M})$ \\
\hline Free cis+siRNAs & $51.63 \pm 10.76$ & $2.25 \pm 0.15$ & $15.79 \pm 2.99$ \\
NCP-1 & $45.77 \pm 12.42$ & $2.10 \pm 0.09$ & $12.72 \pm 0.68$ \\
NCP-1/siBcl-2 & $1.17 \pm 0.18$ & $2.02 \pm 0.15$ & $0.30 \pm 0.20$ \\
NCP-1/sisurvivin & $3.62 \pm 0.15$ & $2.11 \pm 0.17$ & $0.52 \pm 0.09$ \\
NCP-1/siRNAs & $0.14 \pm 0.06$ & $1.89 \pm 0.02$ & $0.14 \pm 0.09$
\end{tabular}

